\title{
Facilitating Digital Transformation in Construction-A Systematic Review of the Current State of the Art
}

\author{
Ayokunle O. Olanipekun * and Monty Sutrisna \\ School of Built Environment, Massey University, Auckland, New Zealand
}

There is increasing implementation of digital technologies in construction. However, the transformation effects encompassing digital technology implementation are yet to be fully comprehended within the context of construction. Therefore, this study was aimed to provide a holistic understanding of digital transformation in construction. The study drew on extant literature by studying 36 journal publications published between 2016 when digital transformation emerged in construction from the information systems field and 2020. This led to the development of an inductive framework using a grounded theory methodology (GTM) to highlight digital transformation in construction as a process where the implementation of digital technologies creates transformation effects that trigger strategic considerations for putting in place the enablers that facilitate transformation effects and for suppressing the barriers to it. Building on the framework, this study described and presented the strategic considerations for facilitating specific enablers and those for suppressing specific barriers as digital transformation guideline in construction. This study demonstrated how the implementation of digital technologies has increased the understanding of and provided the basis for digital transformation in construction.

Chansik Park

Edited by:

Zhen Chen,

University of Strathclyde,

United Kingdom

Chung-Ang University, South Korea Samad Sepasgozar, University of New South Wales,

Australia

${ }^{*}$ Correspondence:

Ayokunle O. Olanipekun olanipekun1439@yahoo.com A.Olanipekun@massey.ac.nz

Specialty section: This article was submitted to Construction Management,

a section of the journal Frontiers in Built Environment

Received: 29 January 2021 Accepted: 07 June 2021

Published: 09 July 2021

Citation:

Olanipekun AO and Sutrisna M (2021) Facilitating Digital Transformation in Construction-A Systematic Review of

the Current State of the Art. Front. Built Environ. 7:660758. doi: 10.3389/fbuil.2021.660758

\section{INTRODUCTION}

The construction industry is experiencing an increasing implementation of digital technologies such as building information modeling (BIM), augmented and virtual reality (AR/VR), laser scanning, robotics, 3D printing, prefabrication and DfMa platforms, analytics software, blockchain, digital twins, internet of things (IoTs), and machine learning solutions throughout the built asset lifecycle (e.g., project, organization, and industry levels) (Ibem and Laryea, 2014; Koch et al., 2019; Singh, 2019). From the overview of academic research, research analysis reveals not only an increasing implementation but also an adaptation of digital technologies for construction operations (Oesterreich and Teuteberg, 2016; Morgan, 2019; Pan et al., 2020; Zabidin et al., 2020). Globally, industry practitioners comprising construction professionals, construction companies, professional bodies, and government agencies have expressed their preferences for implementing digital technologies in construction. McKinsey \& Company reports that top players in the construction industry agree that digital technologies are critical to their sustenance (Buisman, 2018), and the innovative ones are aggressively implementing them (KPMG, 2019). Some of these technologies, such as BIM, have become the norm in the construction project delivery and on the path to maturity in many companies (Maskuriy et al., 2019b; Zabidin et al., 2020).

The implementation of digital technologies encompasses transformational effects-known as digital transformation (DT). Conceptually, DT refers to the changes (or disruptions) that the 


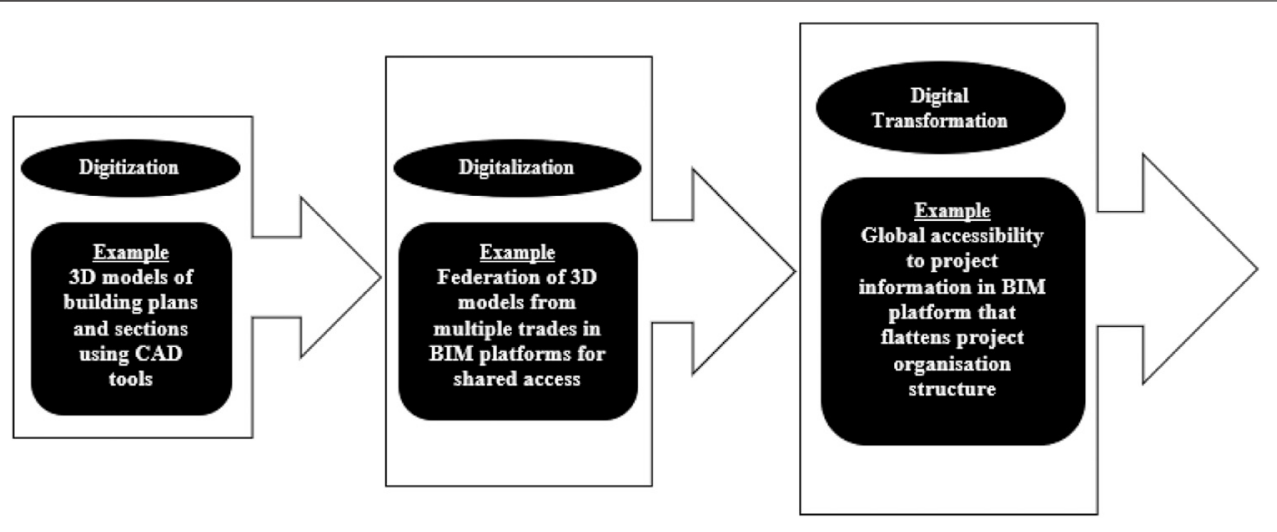

FIGURE 1 | Illustration of digitization-digitalization-digital transformation.

implementation of digital technologies brings to existing business models, which may be experienced in the construction production process, construction companies, and the construction supply chain (Hausberg et al., 2019; Nadkarni and Prügl, 2020). The transformation effects of digital technologies distinguish DT from digitization-which is only the conversion of analog information (e.g., texts, photos, and sounds) into digital information (or binary numbers) that can be encoded by the computer-and digitalization-which is the broader use of digital technologies to optimize existing business processes and functions through enhanced coordination to create more business opportunities and customer value (Verhoef et al., 2019; Berlak et al., 2020). In construction, an example is the old 2D designs on paper, which can now be modeled in 3D using computer-aided designs (CAD) (digitization). Another example is the federation of CAD designs from different trades into the BIM common platform that enables improved project procurement through shared access, clash detection, scheduling, costing, and analytics (digitalization). Lastly, the integration of clients in the building procurement process through augmented interaction with $3 \mathrm{D}$ or higher models or flatter project-organization structure that results from global access to project information in the BIM platform or the evolution of new competencies such as construction informatics are typical examples of transformations resulting from the implementation of digital technologies in construction (DT). Based on the examples, digitization-digitalization-DT appears to be in progression from a preceding one to a succeeding one. In fact, it has been suggested that digitization and digitalization are required to attain DT (Verhoef et al., 2019) (see Figure 1 illustration).

It is notable that the construction industry is close to a "grand" digital technology implementation (Murray, 2018; Autodesk, 2020), but attempting to progress toward DT will not be easy. DT is about introducing digital technologies and implementing the correct technologies by assessing the business needs, strategizing for the future needs, and developing a roadmap to the future (Murray, 2018; Shapiro et al., 2019). Therefore, there is a need to employ a strategic implementation of digital technologies to facilitate the enablers of DT while suppressing the barriers against it in construction (Pan et al., 2020). Full-scale DT has a wide range of benefits at the industry level (through increased productivity and market share), organizational level (through sustained competitiveness and lowered costs in construction companies), and project level (through improved project performance and safety) in construction (Agarwal et al., 2016). In terms of the monetary estimate, these benefits can sum to USD\$1.2 trillion in the residential sector alone by 2025 (Gerbert et al., 2016). Meanwhile, DT is not all about positive outcomes. Negative outcomes such as loss of investments, loss of jobs, and loss of the identity of the construction industry to digital technologies are possible, particularly in a construction industry characterized by fragmentation, lack of replication, transience, and decentralization, making DT very challenging (Koeleman et al., 2019). Therefore, DT must be attempted correctly to maximize the benefits and minimize the negative outcomes.

With the recent aggregation of the literature revealing an increasing implementation of digital technologies (Maskuriy et al., 2019a; Maskuriy et al., 2019b; Zabidin et al., 2020), the transformational effects of these technologies will begin to materialize as DT in construction. Meanwhile, current research on DT in other fields of knowledge such as information systems (IS) (Vial, 2019), business economics (Reis et al., 2018), and interdisciplinary management (Henriette et al., 2015; Verhoef et al., 2019; Nadkarni and Prügl, 2020) has not provided an adequate understanding of DT in construction. Therefore, how construction stakeholders can respond and adapt to DT is not currently known. This study aimed to take stock of the current knowledge through a literature review to provide an understanding of DT in construction. It is hoped that this study will aid construction stakeholders' response and adaptation to DT in construction. The first research objective is to propose an inductive research approach that employs a GTM to review the literature. The approach provides an explorative guideline of research on DT in construction. The second objective is to identify and describe the following: the strategic considerations for implementing digital technologies in construction, the enablers that facilitate DT in construction, and the barriers that suppress it. The third objective is to present and describe an illustrative framework of how the 
strategic considerations facilitate and suppress specific enablers and barriers of DT in construction, respectively. This study offers two contributions. The first one is a review that integrates current knowledge on DT in construction. The second one is providing avenues for developing a guideline for DT in construction.

\section{BACKGROUND}

\section{Digital Transformation Concept}

The increasing use of digital technologies such as virtual reality gadgets and smartphones and their tendencies to disrupt existing business practices and competition landscapes and causing changes to end users' behaviors in response to the technologies has been the bedrock underpinning the conceptualization of digital transformation (DT) in the literature. There is a wide range of digital technologies that are implemented in construction, and they can be divided into four components, including digital data, automation system, digital access, and connectivity (Dallasega et al., 2018; Heusler and Kadija, 2018). Digital technologies generate data when used (Vial, 2019); for instance, wearable sensors and smart meters are used as a collection point of digital data in construction (Craveiroa et al., 2019). The automation systems use digital technologies to create self-organizing systems such as robots for lifting objects on sites (Berlak et al., 2020) and blockchain for executable payment to contractors (Li et al., 2019). Deriving from automation systems is digital access, which is the opportunity afforded by mobile access to internet networks to execute solutions in real time such as data analytics and processing to make on-the-spot decisions or make future predictions (Berger, 2016; Buisman, 2018; Maskuriy et al., 2019b). Connectivity or network encompasses the linking and synchronizing separate activities such as 3D model development and energy-use simulation in the BIM platform (Keskin et al., 2020) or linking the physical-to-digital-to-physical in construction using sensors, cloud computing, IoT, augmented reality, and virtual reality (Craveiroa et al., 2019). Originally, DT evolves from the domains of business transformation strategy and IS (Ismail et al., 2017). Business process transformation establishes new ideas, concepts, opportunities, and competitive strategies to drive business processes, while the IS domain employs information and communication technology to trigger business transformations. As this evolution germinates over the years, the impact has brought about radical changes in business management in the project and organizational contexts (Morakanyane et al., 2017). The changes have been coined into the buzzword known as digital transformation (DT). DT can be regarded as adopting digital technologies to optimize business performance (Henriette et al., 2015). Meanwhile, it is not just about technologies but the changes taking place due to the adoption of digital technologies (Verhoef et al., 2019). The changes or effects are often the creation and addition of value to the existing business (Hausberg et al., 2019) and sometimes a reduction in business value. The addition of value could improve customer experiences of digitally enabled products and services (Verhoef et al., 2019), enhance employee skills and talents (Ismail et al., 2017), and achieve competitive business models (Morakanyane et al., 2017; Reis et al., 2018). DT can also be defined in terms of the individual, organizational, societal, and industry levels where disruptions resulting from digital technologies' adoption occur. As the proliferation and adoption of digital technologies trigger disruptions in the general society or a specific industry, businesses adopt digital technologies to alter their value creation process in response to the disruptions. Therefore, DT is a process whereby digital technologies play a crucial role in creating and reinforcing disruptions around with strong consequences for business performances (Ismail et al., 2017; Reis et al., 2018). Given the wide range of the digital technologies, DT guideline for implementing them correctly should be put in place to maximize their transformation impacts in construction.

\section{METHODOLOGY}

An inductive approach to the literature review was selected in line with the aim of taking the current stock of knowledge to provide an understanding of DT in construction. This study followed the procedures advocated by Sutrisna and Setiawan (2016a) and Wolfswinkel et al. (2013) by employing their procedural steps adapted from grounded theory methodology (GTM) analysis to review the literature. As illustrated in Table 1, the guidelines are divided into six steps and thirteen substeps that guided the review process, from the definition of the scope of review to the presentation of findings. In the approach, the outcome in a step is used to perform the succeeding step (Hausberg et al., 2019) to ensure a transparent and replicable process of analyzing the literature on DT in construction (Nadkarni and Prügl, 2020).

\section{Step 1-Setting the Scope of the Review}

The scope of this review is to focus on the research contributions to DT in the construction domain. DT is basically the impact of digital technology implementation, and it is still unveiling in both practice and research in the construction sector. Therefore, focusing on this sector only helped to be sensitive to emerging concepts in the analysis and obtain in-depth understanding, instead of focusing on research contributions across multidisciplinary sectors, such as the work of Verhoef et al. (2019). Meanwhile, it was recognized that the construction operates at multiple levels, mainly the project, organizational, and industry levels. These levels were included in the preliminary/ descriptive analysis to avoid contextual bias. Also, due to the emerging nature of the subject, no specific time frame was set in the scoping to allow the date of research publications to emerge from the data.

\section{Step 2-Selecting Sources of Research Contributions}

In this step, Google Scholar, Scopus, and Web of Science (WoS) have been identified as the databases to source for data. One of the reasons was that these databases are domain sensitive; they cover more quality research publications than other online sources 
TABLE 1 | Grounded theory methodology style of analysis for literature review.

\begin{tabular}{|c|c|}
\hline Step & Task(s) \\
\hline Step $1-$ Setting the scope of the review & - Define a domain of research \\
\hline Step 2-Selecting sources of research contributions & $\begin{array}{l}\text { - Identify a database to source data } \\
\text { - Select the type of publication }\end{array}$ \\
\hline Step 3-Selection of keywords & - Identify a criterion for the search term \\
\hline Step 4-Screening process & $\begin{array}{l}\text { - Search databases using the search term } \\
\text { - Scan publications } \\
\text { - Filter publications } \\
\text { - Repeat search query } \\
\text { - Download publications }\end{array}$ \\
\hline Step 5-Eligibility & - In-depth analysis using inclusion/exclusion criteria \\
\hline Step 6-Coding structure and analysis & $\begin{array}{l}\text { - Open coding } \\
\text { - Axial coding } \\
\text { - Selective coding }\end{array}$ \\
\hline
\end{tabular}

(Chadegani et al., 2013), especially construction research publications (Maskuriy et al., 2019b). Within these databases, peer-reviewed journal publications were the main targets. Compared to conference papers and practitioner reports, construction journal publications undergo a more rigorous peer-review process. They, therefore, provide a more valid and reliable conceptualization of a subject, especially one that is still emerging as DT in construction. Consequently, academics and practitioners typically prefer the journal type of publication to disseminate new findings (Henriette et al., 2015).

\section{Step 3-Selection of Keywords}

In this step, a preliminary search in the Google scholar database was made to identify the keywords and search terms for the review. It was observed that DT is the generic keyword used in multidisciplinary disciplines (Verhoef et al., 2019), but it is also used in describing the impact of implementing digital technologies in the construction sector [e.g., (Bonanomi et al., 2019)]. Therefore, a criterion for the search term that includes a general keyword to account for the impact of the implementation of digital technologies ("digital transformation") and a domainspecific keyword ("construction") was adopted. The search terms using the combination of "digital transformation" AND "construction" were designed to collect data. It was acknowledged that keywords such as "digitization" and "digitalization" could be relevant but the search term combination adequately fits the criterion specified.

\section{Step 4-Screening Process}

The search process using the keywords search combination in the databases generated up to 5797 publications in July 2020. This is a large number caused by the broad keywords, especially "construction," which can convey other meanings than describing a sector (semantics). The publications were scanned by title followed by reading the abstracts of those relevant to the aim of the study (Wolfswinkel et al., 2013; Verhoef et al., 2019). Because multiple databases were employed, duplications and peer-reviewed publications that are not journals were filtered. Examples are conference papers published in ScienceDirect procedia and Springer publication outlets. Part of the filtration was removing those publications not written in English to prevent us from wrong interpretations (Reis et al., 2018). After reading the abstracts and the filtration, it narrowed down to 151 publications. Before downloading the publications in the PDF format in the Endnote, the search query was repeated against them to check that they are rightly included for a more in-depth review (Chadegani et al., 2013).

\section{Step 5-Eligibility}

As mentioned above, the 151 publications were subjected to a more in-depth study and analysis using more rigorous inclusion/ exclusion criteria to select publications that qualified for the final sample as follows: 1) publications were required to primarily focus and contribute to DT in the construction sector, including the project, organizational, and industry levels of construction operation [e.g., Bonanomi et al. 's (2019) study on the impact of DT on the organizational structures in large AEC firms]; 2) publications were required to use DT as the theoretical lens of research and may use this theoretical lens: propose hypotheses; identify the research variables; for data collection; for explaining research findings; and to drawing conclusions and recommendations; and 3) publications that are neither 1) nor 2) were excluded; such publications are more practitionercentered offering insights on the implementation of digital technologies to relevant stakeholders [e.g., Deraman et al., 2019; Soman and Whyte, 2020; Zima et al., 2020]. The eligibility process resulted in a final sample of 36 journal publications that met the criteria. The publications within the sample were published within a time frame from 2016 to 2020, 35 of which were published between 2018 and 2020. This indicates that research on DT in construction is just emerging, deriving from DT as a topic of research that has only emerged about 5-10 years ago from the broader field of IS (Ismail et al., 2017; Nadkarni and Prügl, 2020).

\section{Step 6-Coding Structure and Analysis}

Following Wolfswinkel et al.'s (2013) suggestion, each publication within the final sample was randomly picked to code the contents using the coding structure in Table 2.

The coding structure is divided into two parts. The first one is the descriptive information of the journal publications comprising three categories, namely, publication field, nature, 
TABLE 2 | Coding structure of the final sample.

\section{Coding structure}

Descriptive information of journal publications

Concepts/main points of focus

\begin{tabular}{|c|c|c|}
\hline \multirow[t]{4}{*}{ Publication field } & Construction & $\begin{array}{l}\text { Information technology journals in construction } \\
\text { Generic/common construction journals }\end{array}$ \\
\hline & Information technology & \\
\hline & Economics & \\
\hline & Health & \\
\hline \multirow[t]{3}{*}{ Nature of the study } & Empirical & Quantitative studies \\
\hline & & Qualitative studies \\
\hline & Conceptual & \\
\hline \multirow[t]{29}{*}{ Context of the study } & Industry & \\
\hline & Organisational & \\
\hline & Project & \\
\hline & Strategic considerations & Process \\
\hline & & Collaboration \\
\hline & & Learning \\
\hline & & Value \\
\hline & & Lifecycle \\
\hline & Enablers & Choice of digital \\
\hline & & Data \\
\hline & & Digital champions \\
\hline & & Attraction of digital \\
\hline & & Training opportunities \\
\hline & & Innovativeness \\
\hline & & System support \\
\hline & & Organization structure \\
\hline & & Digital culture \\
\hline & & Legitimation \\
\hline & & Research \\
\hline & Barriers & Data processing \\
\hline & & Data access and ownership \\
\hline & & System integration \\
\hline & & Standardization \\
\hline & & ROI uncertainty \\
\hline & & Owner buy-in \\
\hline & & Older workers \\
\hline & & Business models \\
\hline & & Digital divide \\
\hline & & System attacks \\
\hline
\end{tabular}

and context of the study. The categories are subdivided into children categories that provide deeper information about the publications. Most of the sources are journals aimed to produce publications on information and technology in construction (36\%). Without undermining the scoping process, five publications from nonconstruction journals (including Computers in Industry, where three publications were sourced) included in the sample are consistent with the selection criteria. These publications indicate an interest from other disciplines in DT in construction. Furthermore, 58\% (21) of the journal publications are empirical studies employing quantitative or qualitative research methodologies, while the rest (15 or 42\%) are conceptual studies. While this contradicts previous findings in research on DT in other fields (Nadkarni and Prügl, 2020; Reis et al., 2018), it suggests more attempts at testing the existing theoretical foundations on DT in construction. Studies seeking to conceptualize the field such as this study are necessary to match the enthusiasm for empirical testing of DT in construction. Finally, consistent with wider implications of DT in different contexts (society, organization, industry, and project contexts) (Keskin et al., 2020; Bharadwaj et al., 2013; Morakanyane et al.,
2017), 55\% of the publications focused on DT in the construction industry context, $28 \%$ on the project context, and $17 \%$ on the organizational context. Interestingly, most conceptual studies $(13 / 15$ or $87 \%)$ focused on the construction industry context. It further reinforces the emerging nature of research on DT in construction, commencing with more research conceptualization of field (conceptual studies) from a higher context, which is the construction industry context.

The second one is the coding structure for the concepts or main points of focus in the sample. It is comprised of three categories, namely, strategic considerations, enablers, and barriers of DT in construction. Similarly, the categories are subdivided into children categories. In this step, the techniques borrowed from the GTM were applied to analyze the texts in the final sample carefully (Böhm, 2004; Sutrisna and Setiawan, 2016b) to develop an understanding of the literature under review (Vial, 2019). Therefore, the three techniques of GTM (open coding, axial coding, and selective coding) were performed. Open coding is the conceptualization and categorization of phenomena through an intensive analysis of the data. Axial coding is exploring and identifying the relationships between 


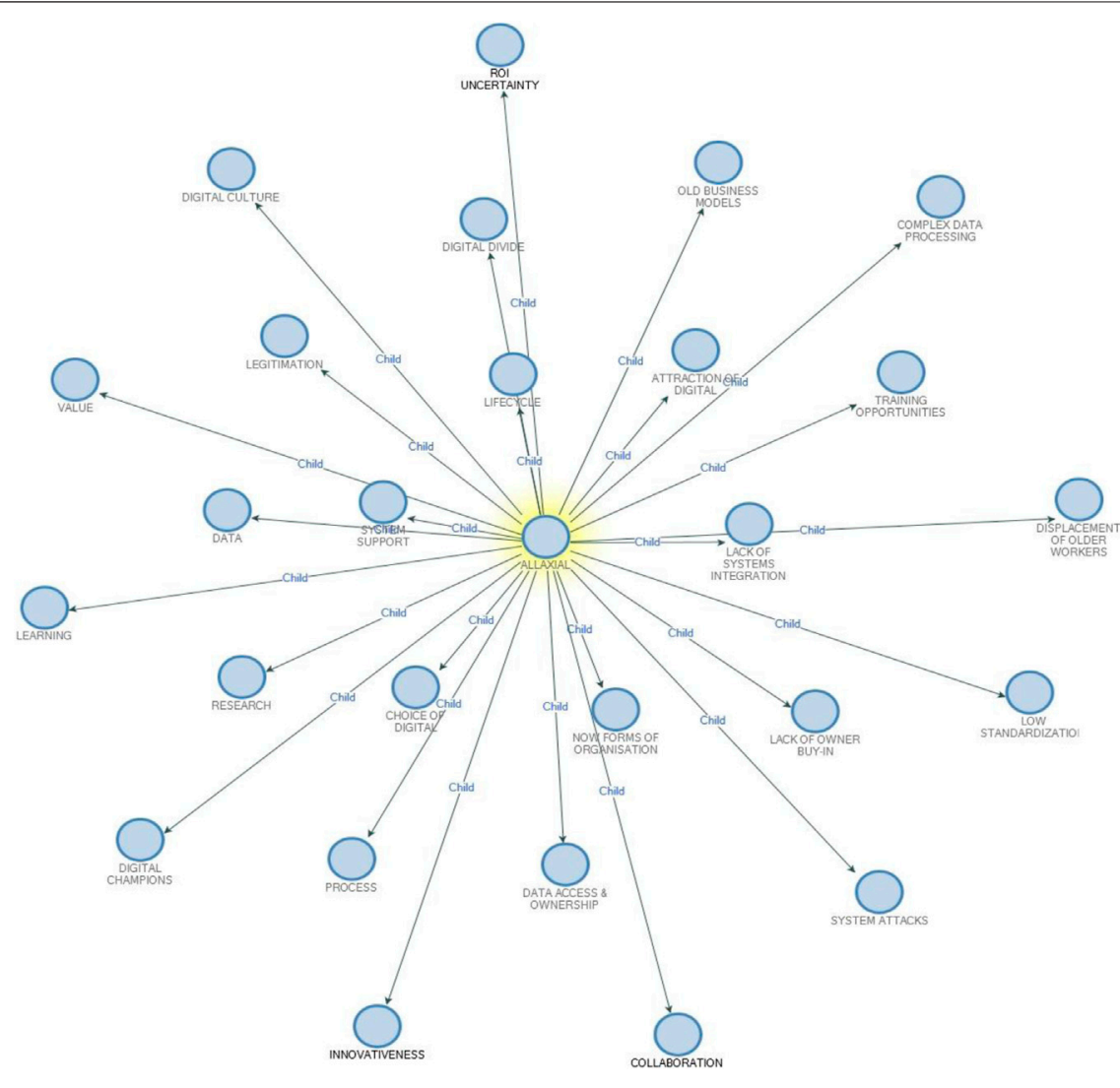

FIGURE 2 | NVivo explore diagram of the second-order categories.

concepts and categories that have been developed in the open coding process. Selective coding is the integration of the different categories that have been developed, elaborated, and mutually related during axial coding into one cohesive whole. Of note is that selective coding is quite like axial coding, except that it is carried out on a more abstract level.

The open coding was carried out by interrogating the main text in the 36 publications regarding the findings, discussions, concluding parts, and other relevant parts, while also taking notes to summarize each publication in the NVivo software (Hull, 2013; Sutrisna and Setiawan, 2016a; Nadkarni and Prügl, 2020). This led to the first abstraction of the concepts in the sample. Four hundred and twenty-three (423) first-order categories through the open coding were identified at this point. In the following axial coding, there was a search for the meanings and patterns in the open codes to assemble them into second-order categories in the NVivo. As an example, the first-order categories such as "concerns about the exchange of information" and "inconsistent standards" were placed under a second-order category coded "Low standardization." Consistent with GTM to ensure a gradual discovery, the publications and open codes were revisited iteratively and noting new insights in a separate document. The coding instances were much reduced after a round to retain the 26 second-order categories through axial coding and presented using the NVivo Explore Diagram in Figure 2.
Selective coding was the last technique that represented the highest level of abstraction in our coding, where we endeavored to integrate the second-order categories. It is at this point that we further reduced the 26 second-order categories into three main categories. They are strategic considerations, enablers, and barriers of DT in construction and illustrated in Figure 3.

In line with the GTM, the analysis was designed to ascend from one level of abstraction per time, commencing with the descriptive information of the sample, followed by the storyline or node summary of the main categories and children categories of the concepts or main points of focus in the sample (open coding, axial coding, and selective coding). Finally, the mapping tree of the interaction of the categories is presented to discuss the findings. This analysis procedure is represented in Figure 4. Furthermore, as mentioned previously, memoing new insights in a separate document in the iterations in the coding process was carried out (Webster and Watson, 2002; Hull, 2013; Sutrisna and Setiawan, 2016b).

Meanwhile, a separate analysis of the publications was carried out to reveal construction activity fields and their digital transformation using an inductive content analysis method. This method was used in conformity with the earlier inductive approach to literature review (or data collection) due to the emergent nature of the subject of investigation (Kyngäs, 2020). The first step involved data reduction-where the first author 


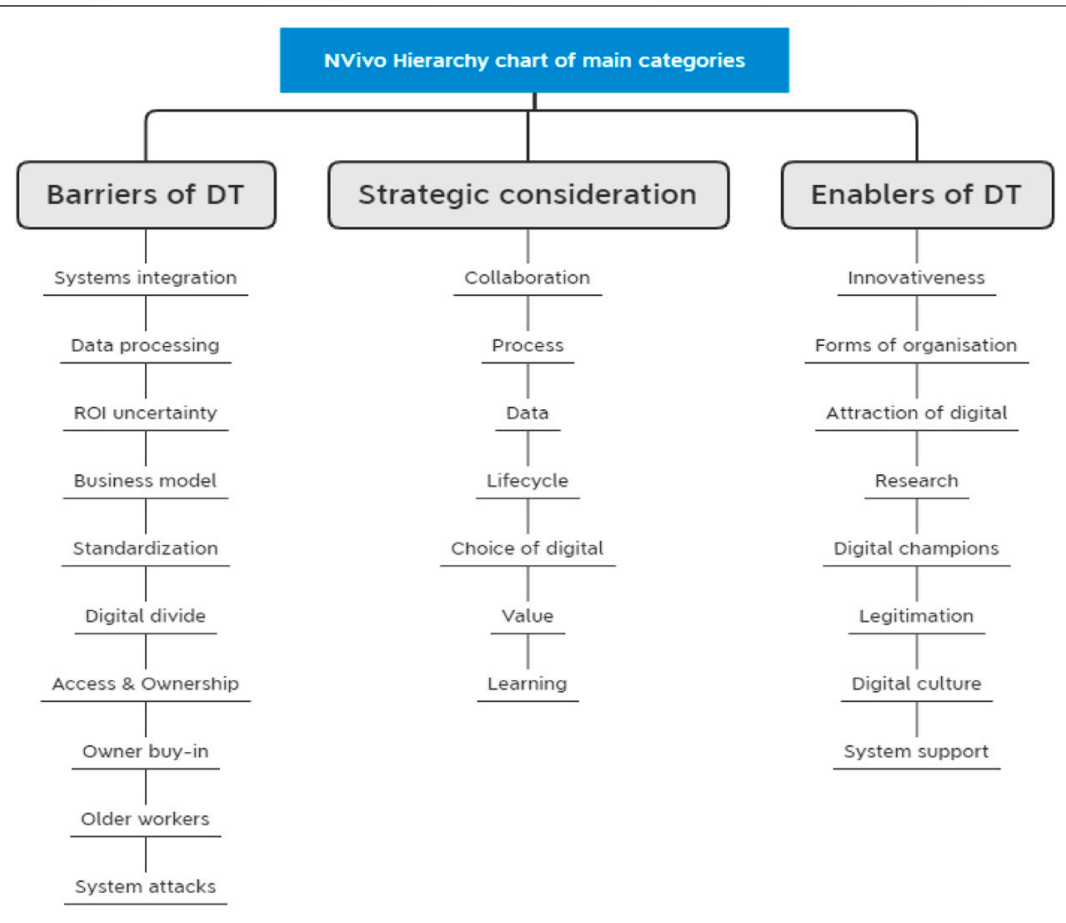

FIGURE 3 | NVivo hierarchy chart of the main categories (redesigned by authors).

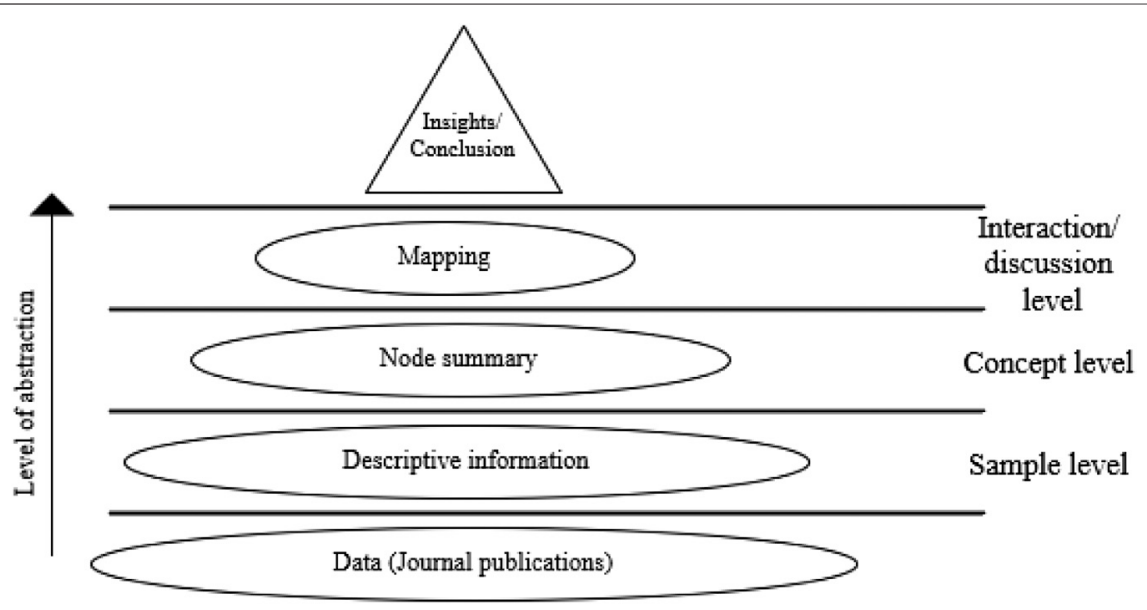

FIGURE 4 | Analysis procedure.

carried out further reading of the 36 publications to identify and select the ones that focused on the implementation of specific digital technologies in their analysis. For instance, Craveiroa et al. (2019) focused on the application of 3D printing for architectural and engineering designs and was selected. Aghimien et al.'s (2020a) study was not selected for exploring digital partnering from professional perspectives only. Of the 36 publications, 19 of them met this criterion and were selected. The second step involved data grouping where the second author, an experienced researcher in qualitative studies [e.g., Sutrisna and Setiawan, 2016b], identified construction activity fields that were implemented in the 19 publications. This author used MS Excel to tabulate the digital technologies in "rows" and "construction activity fields" in columns for cross analysis and descriptions. The construction activity fields refer to project-based tasks such as physical construction (Koseoglu et al., 2019) and organization processes such as interfirm relations (Hetemi et al., 2020) that feature in project delivery and asset lifecycle. The last step involved formation of concepts. Both the authors were involved, using the table produced in the previous step to extract the applications of digital technologies to specific construction activity fields in the publications. There was need 


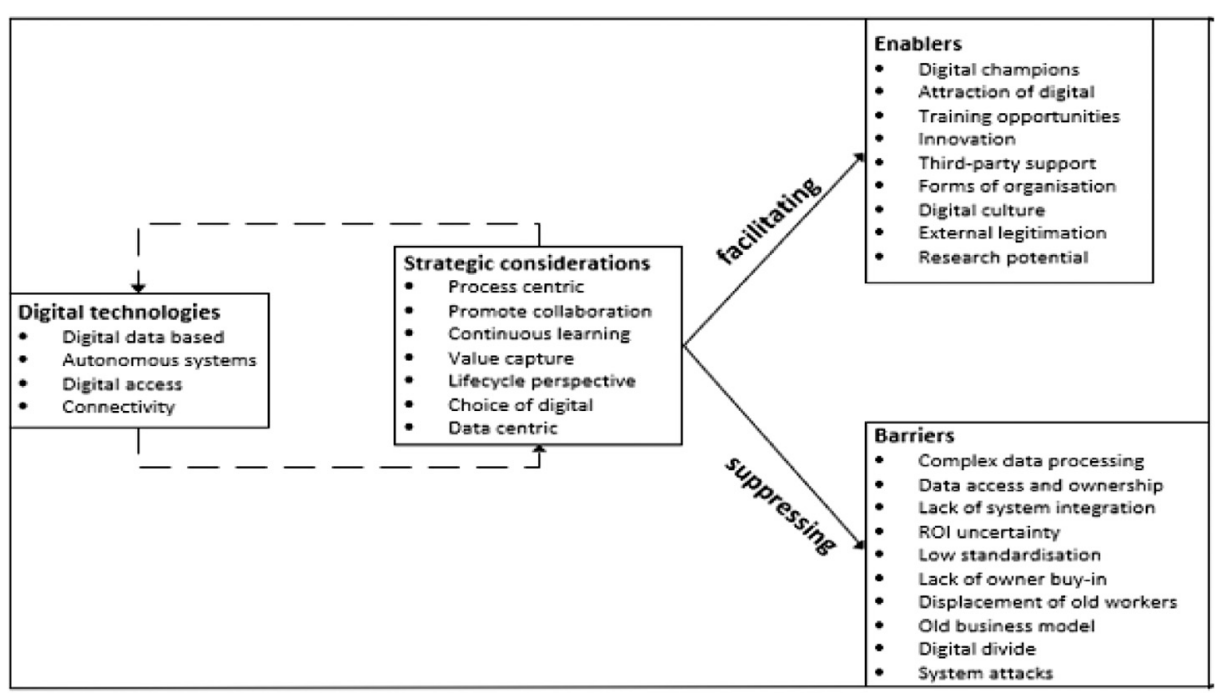

FIGURE $\mathbf{5}$ | Concepts of DT in construction.

to reconcile construction activity field of application of a digital technology, for instance, whether BIM is applicable to either one or both supply chain integration and interfirm relations (Hetemi et al., 2020). The authors extracted both activity fields and retained because the same digital technology (e.g., BIM) was applied to the activity fields in other publications in the sample [e.g., Berlak et al., 2020].

\section{FINDINGS}

\section{Inductive Framework of Digital Transformation in Construction}

The inductive framework condensing the existing knowledge on DT in construction is presented in Figure 5. As mentioned in step 6 in the methodology section, the framework illustrates the concepts of DT in construction emerging from the open coding, axial coding, and selective coding of the sample as follows. First, DT is the process where the implementation of digital technologies creates transformational effects. Second, the transformation effects trigger strategic considerations from the implementers of digital technologies, which, third, helps to 1) put the enablers that facilitate transformation efforts in place and 2) suppress the barriers to the transformation efforts.

\section{Strategic Considerations of Digital Technologies in Construction}

Successful DT requires strategic consideration of digital technologies (Buisman, 2018; Aghimien et al., 2020a). As shown in Table 2 and Figures 2, 3, the results of the open coding, axial coding, and selective coding produce seven strategic considerations for implementing digital technologies, namely, process, collaboration, learning, value, lifecycle, choice of digital, and data. Of note, these considerations point mainly to "how" digital strategies may be developed to implement digital technologies in construction rather than specifying actual digital strategies. They are described in this section, and the summary of the literature on the strategic considerations is presented in Table 3.

\section{Process}

Process-centric strategic consideration suggests systematic implementation of digital technologies and has been found to foster DT in construction (Li et al., 2019; Aghimien et al., 2020b). This strategic consideration aligns the implementation of digital technologies procedurally with the construction project lifecycle phases (Koseoglu et al., 2019; Morgan, 2019), for instance, initially implementing BIM in the design and construction phases and later implementing the tool at the building operation phase. A study revealed that the process-centric strategy was employed in the blockchain implementation, which proceeded in a controlled manner according to project lifecycle phases (Li et al., 2019). In this manner, the impacts resulting from the blockchain implementation, such as bypassing extant regulations, were better controlled and evaluated ( $\mathrm{Li}$ et al., 2019). Also, digital technologies can be very disruptive. The process-centric strategic consideration allows an incremental implementation of digital technologies, which helps control the rate of diffusion of implemented technology before reaching the disruptive stage (Deraman et al., 2019; Morgan, 2019).

\section{Collaboration}

The strategic consideration for digital technology implementation should promote collaboration and interaction among stakeholders in the construction supply chain (Dallasega et al., 2018; Craveiroa et al., 2019; Keskin et al., 2020). With respect to BIM, a recent study found that most stakeholders who implement it are still immature and often struggle with basic 
TABLE 3 | Summary of literature on strategic considerations.

\begin{tabular}{|c|c|}
\hline Strategic considerations & Sources \\
\hline Process $(\mathrm{n}=11)$ & $\begin{array}{l}\text { Goulding et al. (2018), Heusler and Kadija (2018), Woodhead et al. (2018), Braun and Sydow (2019), Craveiroa et al. (2019), } \\
\text { Koseoglu et al. (2019), Li et al. (2019), Morgan (2019), Aghimien et al. (2020b), Hetemi et al. (2020), and Succar and Poirier } \\
\text { (2020) }\end{array}$ \\
\hline Collaboration $(n=14)$ & $\begin{array}{l}\text { Oesterreich and Teuteberg (2016), Dallasega et al. (2018), Heusler and Kadija (2018), Papadonikolaki (2018), Woodhead } \\
\text { et al. (2018), Koseoglu et al. (2019), Papadonikolaki et al. (2019), Singh (2019), Aghimien et al. (2020a), Aghimien et al. } \\
\text { (2020b), Craveiroa et al. (2019), Darko et al. (2020), Hetemi et al. (2020), and Keskin et al. (2020) }\end{array}$ \\
\hline Learning $(n=4)$ & Dallasega et al. (2018), de Soto et al. (2018), Chen (2019b), and Aghimien et al. (2020b) \\
\hline Value $(\mathrm{n}=9)$ & $\begin{array}{l}\text { Dallasega et al. (2018), Maskuriy et al. (2019a), Craveiroa et al. (2019), Aghimien et al. (2020b), Darko et al. (2020), Greif et al. } \\
\text { (2020), Hetemi et al. (2020), Pham et al. (2020), Tezel et al. (2020), and Winch and Cha (2020) }\end{array}$ \\
\hline Lifecycle $(n=8)$ & $\begin{array}{l}\text { Papadonikolaki (2018), Woodhead et al. (2018), Chen (2019a), Koseoglu et al. (2019), Aghimien et al. (2020b), Keskin et al. } \\
\text { (2020), Newman et al. (2020), and Succar and Poirier (2020) }\end{array}$ \\
\hline Choice of digital $(n=7)$ & $\begin{array}{l}\text { Dallasega et al. (2018), Braun and Sydow (2019), Koseoglu et al. (2019), Aghimien et al. (2020a), Newman et al. (2020), Pan } \\
\text { et al. (2020), and Pham et al. (2020) }\end{array}$ \\
\hline Data $(n=3)$ & Woodhead et al. (2018), Braun and Sydow (2019), and Pham et al. (2020) \\
\hline
\end{tabular}

understanding of how it fosters stakeholder collaboration (Yang and Chou, 2019). It becomes apparent that strategic consideration should promote collaboration in a virtual environment, such as those apparent with the platforms for BIM tools (Koseoglu et al., 2019). The benefit is a synergistic working relationship among stakeholders (Dallasega et al., 2018) and greater project performance (Papadonikolaki, 2018; Papadonikolaki et al., 2019). In practice, the strategic consideration that promotes collaboration can be experienced as digital partnering among project organizations to share digital resources (Lavikka et al., 2017; Aghimien et al., 2020a). Furthermore, it could be a technology-enabled collaborative ecosystem (Aghimien et al., 2020a) where digital technologies coevolve across software, hardware, products, people, and process (Singh, 2019; Hetemi et al., 2020; Keskin et al., 2020). Therefore, the strategic consideration specifies how people and machine can be connected, especially in large-scale infrastructure projects (Keskin et al., 2020). This strategic consideration needs to be in place to guide the implementation of cobots (collaborative robots) to work with humans in construction environments (Darko et al., 2020).

\section{Learning}

Technology always does change, whereby the starting point is often discreet and the learning curve is never-ending (Buisman, 2018). Seemingly, new digital technologies are produced on an incremental basis that often results in subsequent model upgrades. This creates a need for continuous learning among digital technology implementers in construction, basically understanding the new features in upgraded digital technologies and applying them correctly (de Soto et al., 2018). Therefore, the strategic consideration for continuous digital learning is necessary and has been found to increase the understanding of the gaps and solutions to digital technology applications in design, construction, and operation phases (Chen, 2019b). The strategic consideration for continuous learning stipulates the feedback process, whereby lessons learnt from implemented digital technologies in construction become inputs for improving future digital technology design and development (Dallasega et al., 2018; Chen, 2019b). The implementation of 3D printing technology in the manufacturing sector is considered. Continuous learning among construction stakeholders has been found useful to adapt the technology in the construction sector (Chen, 2019b). Consequently, the technology is gradually becoming domain specialization in construction (Dallasega et al., 2018).

\section{Value}

It is important to identify the quantitative and qualitative benefits that could be derived from the implementation of digital technologies in construction (Darko et al., 2020). This corresponds to value capture and can be achieved by developing business cases that specify the value added by using digital technologies in construction (Winch and Cha, 2020). Therefore, strategic consideration for implementing digital technologies should incorporate business case development (Tezel et al., 2020; Winch and Cha, 2020). The business case of digital technologies reveals benefits and/or value added in the short and long terms. For digital technologies with a high initial cost, such as 3D printing, the business case should specify the value added in the long term (Craveiora, 2019). Such technologies are more likely to deliver higher value when used over a long period (Craveiroa et al., 2019). Similarly, the use of AI technologies can be costly in terms of money, time, and complexity; therefore, the business case should be developed to cover a long-term period (Darko et al., 2020). In sum, business case development capturing the value of digital technologies is a strategic way of justifying investment in digital technologies in construction in both the short and long terms (Greif et al., 2020; Hetemi et al., 2020).

\section{Lifecycle}

Increasingly, digital technologies such as the cloud technology that support lifecycle project implementation are being produced. Cloud technology is used for automating lifecycle tasks in construction (Keskin et al., 2020), such as lifecycle information exchange, as demonstrated in the work of Succar and Poirier (2020). Therefore, strategic consideration should envision and support the implementation of digital technologies over the project lifecycle. This ensures that the transformation impacts 
can be experienced over the built asset lifecycle (Koseoglu et al., 2019; Keskin et al., 2020). For instance, the BIM execution plan is an operational strategy for BIM implementation not just at the project design stage but throughout the project lifecycle. According to Papadonikolaki (2018), extending BIM implementation to the end of the built asset lifecycle through facility management has increased BIM implementation and impacts in the construction supply chain and many construction organizations The consequence, which can also be observed in IoT implementation, has helped construction organizations to adapt better to digital evolutions (Woodhead et al., 2018) that guarantee positive outcomes (Newman et al., 2020).

\section{Choice of Digital}

Implementing digital technologies should not be an arbitrary choice despite the amazing benefits of enhancing construction processes (Newman et al., 2020). There should be a deliberate attempt to identify and select the type of digital investment in construction (Dallasega et al., 2018; Newman et al., 2020). Therefore, a strategic consideration that guides the choice of digital investment is needed. Importantly, strategic consideration is needed to comprehend diverse digital tools and when they should be deployed (Newman et al., 2020). This is relevant to ensure that digital technologies are implemented only where efficiency of construction tasks can be achieved and vice versa (Newman et al., 2020). For instance, the potential of using robots to improve efficiency on construction sites is still shrouded in uncertainty (Pan et al., 2020) and this has increased the need to identify the digital technologies that are easier and less burdensome to implement (Dallasega et al., 2018). Particularly, in small organizations, digital technologies that are simple and familiar and better adaptable to the operation process should be a strategic choice (Pham et al., 2020). Project, time, size, and duration are additional factors that should be considered in determining the choice of digital technologies in construction (Koseoglu et al., 2019). Finally, an entire set of very diverse capabilities is needed for utilizing new technologies (Braun and Sydow, 2019; Aghimien et al., 2020a), and the availability of these capabilities should be strategically considered in the choice of digital investments in construction (Braun and Sydow, 2019).

\section{Data}

Enormous data are increasingly generated in the construction process (Woodhead et al., 2018). It is of strategic importance to consider making such data available (Buisman, 2018) from one technology to another (Pham et al., 2020), from a physical to a virtual world (Woodhead et al., 2018), and from one construction phase to another (Braun and Sydow, 2019). This increases the potential of data analytics in construction, which contributes to smart management and sound decision making (Woodhead et al., 2018; Pham et al., 2020). Data-centric strategic consideration is very relevant for implementing digital technologies such as drones, robots, and $3 \mathrm{D}$ printing to perform tasks on construction sites without human inputs (Woodhead et al., 2018). A strategic consideration that specifies the requirements of such technologies is necessary, for instance, to ensure that they are capable of concurrent copying of data streams to multiple destinations such as a database or analytics engine (Woodhead et al., 2018).

\section{Enablers of Digital Transformation in Construction}

Enablers facilitate successful/beneficial DT in construction. As shown in Table 2 and Figures 2, 3, the results of the open coding, axial coding, and selective produce the nine enablers of DT in construction, namely, digital champions, the attraction of digital, training opportunities, innovativeness, system support, and new forms of organization. Others are digital culture, legitimation, and research. They are described in this section, and the summary of the literature on the strategic considerations is presented in Table 4.

\section{Digital Champions}

The implementation of digital technologies in construction produces digital leaders who are known as digital champions (Morgan, 2019). Taking an example of BIM implementation, BIM champions are distinguished from adopters-only by emphasizing institutional outcomes beyond implementationonly (Azzouz and Papadonikolaki, 2020), such as digital knowledge networking (Azzouz and Papadonikolaki, 2020; Hetemi et al., 2020). Digital champions can be construction and project leaders who imbibe a strong commitment to implement digital technologies even when inconvenient (Chen, 2019a; Aghimien et al., 2020b). Such commitment can be exemplary for operation-level employees in construction (Berlak et al., 2020) and has been found to motivate them to become digital champions (Bonanomi et al., 2019). At the organization level, digital champions have been found to encourage the interorganizational application of digital technologies through digital partnerships (Aghimien et al., 2020b). Furthermore, digital champions facilitate DT at the institutional level, ensuring that the application of digital technologies by digital agents (users) conforms with professional institution rules and standards in the construction industry (Morgan, 2019).

\section{Attraction of Digital}

The use of digital technologies has become an attraction point that accelerates DT in construction due to the possibilities of performing tasks digitally. With digital technologies, the construction skill-base is digitally empowered (Craveiroa et al., 2019), and construction processes are transformed (de Soto et al., 2018). Studies have identified the emergence of new construction skills (e.g., construction informatics and block chaining) (Tezel et al., 2020), displacement of jobs such as traditional cost quantification (de Soto et al., 2018), and the evolution of new tasks such as sensor monitoring (Woodhead et al., 2018) as transformations that emerged following the use of digital technologies in construction. The enthusiasm for such transformations is greater among the young generation of construction employees who are keen to use new technologies and deploy new ways of working (Pham et al., 2020; Soman and 
TABLE 4 | Summary of inductive literature on enablers of DT in construction.

Enablers

Digital champions $(\mathrm{n}=8)$

Attraction of digital technologies $(n=17)$

Training opportunities $(n=15)$

Innovativeness $(\mathrm{n}=12)$

Third-party support $(\mathrm{n}=11)$

New forms of organization $(n=15)$

Culture inclusion $(n=10)$

External legitimation $(n=8)$

Research potential $(n=6)$
Sources

Woodhead et al. (2018), Chen (2019a), Bonanomi et al. (2019), Morgan (2019), Aghimien et al. (2020b), Azzouz and Papadonikolaki (2020), Berlak et al. (2020), and Hetemi et al. (2020)

de Soto et al. (2018), Goulding et al. (2018), Heusler and Kadija (2018), Woodhead et al. (2018), Braun and Sydow (2019), Craveiroa et al. (2019), Koseoglu et al. (2019), Li et al. (2019), Papadonikolaki et al. (2019), Singh (2019), Hetemi et al. (2020), Newman et al. (2020), Pan et al. (2020), Pham et al. (2020), Tezel et al. (2020), and Winch and Cha (2020)

Goulding et al. (2018), Woodhead et al. (2018), Maskuriy et al. (2019b), Koch et al. (2019), Koseoglu et al. (2019), Li et al. (2019), Singh (2019), Aghimien et al. (2020b), Darko et al. (2020), Greif et al. (2020), Hetemi et al. (2020), Newman et al. (2020), Pan et al. (2020), and Winch and Cha (2020)

Goulding et al. (2018), Papadonikolaki (2018), Woodhead et al. (2018), Chen (2019b), Maskuriy et al. (2019b), Craveiroa et al. (2019), Singh (2019), Azzouz and Papadonikolaki (2020), Hetemi et al. (2020), Keskin et al. (2020), and Pan et al. (2020) Aghimien et al. (2020a); Aghimien et al. (2020b); Berlak et al. (2020); Bonanomi et al. (2019); Braun and Sydow (2019); Chen (2019b); Newman et al. (2020); Pan et al. (2020); Tezel et al. (2020); and Woodhead et al. (2018)

Oesterreich and Teuteberg (2016), Maskuriy et al. (2019b), Bonanomi et al. (2019), Braun and Sydow (2019), Koseoglu et al. (2019), Morgan (2019), Azzouz and Papadonikolaki (2020), Berlak et al. (2020), Darko et al. (2020), Greif et al. (2020), Hetemi et al. (2020), Newman et al. (2020), and Pham et al. (2020)

Dallasega et al. (2018), Woodhead et al. (2018), Maskuriy et al. (2019), Koseoglu et al. (2019), Azzouz and Papadonikolaki (2020), Berlak et al. (2020), Hetemi et al. (2020), Newman et al. (2020), Pan et al. (2020), and Tezel et al. (2020)

Papadonikolaki (2018), Chen (2019a), Koseoglu et al. (2019), Li et al. (2019), Morgan (2019), Papadonikolaki et al. (2019), Hetemi et al. (2020), and Tezel et al. (2020)

Oesterreich and Teuteberg (2016), Dallasega et al. (2018), Chen (2019b), Singh (2019), Pan et al. (2020), and Tezel et al. (2020)
Whyte, 2020). They strengthen their technical skills and soft skills such as communication (Braun and Sydow, 2019; Papadonikolaki et al., 2019; Winch and Cha, 2020), which promotes them from digital talents to digital agents (Goulding et al., 2018; Azzouz and Papadonikolaki, 2020). Encouraging the young generation to use digital technologies to perform construction tasks is key to DT in construction (Koseoglu et al., 2019). Another key aspect is that the construction sector is an intellectual space where digital talents are challenged and cultivated with creative professional opportunities that lead to DT progress (Singh, 2019; Pan et al., 2020). This is accentuated by the limited knowledge of construction in the IT industry, which creates a digital opportunity for construction professionals and practitioners (Woodhead et al., 2018).

\section{Training Opportunities}

The rise of digital technologies invokes an educative agenda ( $\mathrm{Li}$ et al., 2019), manifested in the form of continuous digital training (Aghimien et al., 2020b; Hetemi et al., 2020). The training has increased digital knowledge, skills, and capabilities in construction (Goulding et al., 2018; Li et al., 2019; Aghimien et al., 2020b). Intraorganizational (including project organization) digital training (e.g., facilitated workshops and meetings) is used to shorten the digital learning curve, particularly for young people in construction (Koseoglu et al., 2019; Aghimien et al., 2020b). However, such pieces of training require outsourced specialists (Koch et al., 2019), which is time consuming and expensive in BIM training (Newman et al., 2020). Also, institutionalized training that enables an organic development of digital innovation industry wide is rising (Maskuriy et al., 2019b; Azzouz and Papadonikolaki, 2020). For example, the degree apprenticeship model of undergraduate education has increasingly been used to enhance students' digital capabilities and graduates in the
United Kingdom construction industry (Woodhead et al., 2018). This model underscores the importance of higher education in the journey toward DT in the construction industry. Interindustry digital training is increasing in the construction industry (Goulding et al., 2018; Darko et al., 2020) which, for instance, has been useful to harvest prefabrication and robotics development skills from manufacturing and engineering sectors, respectively (Pan et al., 2020; Singh, 2019).

\section{Innovativeness}

The increasing use of digital technologies has created a fertile environment for construction innovation (Craveiroa et al., 2019; Pan et al., 2020). The commonest one is the use of digital technologies that are primarily domiciled in the manufacturing sector. It has led to the cultivation of an interdisciplinary digital innovation environment that allows construction practices to interface with practices in other sectors (Chen, 2019b). It has also increased technology transfer between the construction and other sectors (Goulding et al., 2018; Singh, 2019). Interestingly, digitally savvy construction clients have capitalized on the interface created (Azzouz and Papadonikolaki, 2020) to learn from other sectors and demand similar digital technology applications in their projects (Woodhead et al., 2018). It now represents how construction clients bring innovation to their projects and, in the process, influencing those involved to use digital technologies in the project delivery process (Hetemi et al., 2020). However, innovation can either be positive or negative. On a positive note, the transformative impact of these innovations increases the implementation of digital technologies. On a negative note, an aggressive could trigger an industry-wide attitude against the use of digital technologies and impair innovation in the process (Koseoglu et al., 2019). 


\section{Third-Party System Support}

The availability of a third-party (system) supports the successful implementation of digital technologies in construction (Aghimien et al., 2020b). Sepasgozar and Loosemore (2017) identified visionaries, innovators, followers, and conservative categories of the interplay that exist between the stakeholders who manufacture digital technologies (or vendors) and the customers who use them in construction. Manufactures who are visionaries provide installation supports (either online or physically) for digital technologies procured for construction purposes (Berlak et al., 2020). Such supports from Autodesk solutions have increased the usage of digital technologies in construction (Newman et al., 2020). Recently, system support has gradually extended to benchmarking the impact of digital technologies on construction performance bottomlines (e.g., productivity and competitiveness) (Berlak et al., 2020). This has increased cocreation between innovative (or innovators) construction stakeholders and manufacturers such as Autodesk to produce customized digital technologies (Woodhead et al., 2018) and transforming existing digital capabilities in the process (Braun and Sydow, 2019). For robotic design and implementation on construction sites, cocreation between construction stakeholders and manufacturers has helped develop real world-class proofs-ofconcept (Pan et al., 2020) by the pragmatists (Sepasgozar and Loosemore, 2017). Another aspect of system support is when construction organizations engage in digital partnership with IT domain organizations (Aghimien et al., 2020a). As demonstrated in a BIM implementation study (Braun and Sydow, 2019), it is conservatively engaging in digital partnerships to avail the digital resources and capabilities that were not present but the key to successful BIM implementation (Bonanomi et al., 2019; Aghimien et al., 2020a).

\section{New Forms of Organization and Restructuring}

New forms of organization encompassing project and organizational relationships, roles and responsibilities, and organizational structure are necessary to derive the full benefits of digital technologies and the transformational impacts in construction (Bonanomi et al., 2019; Darko et al., 2020). Less departmentalized structures allow employees to easily distribute digital knowledge in construction organizations (Bonanomi et al., 2019; Hetemi et al., 2020). The size of construction organizations is important. In both large and small organizations, it is essential to clarify the ease of digital technology diffusion in either type (Morgan, 2019; Newman et al., 2020). Role flexibility that permits construction professionals to engage other responsibilities beyond their primary domain enhances DT, especially in large organizations (Bonanomi et al., 2019; Azzouz and Papadonikolaki, 2020). It allows practitioners to have more room to draw on individual, organizational, and institutional resources to innovate freely (Morgan, 2019). Besides, the flexibility ensures that existing informal roles and relationships are not destroyed but properly aligned with new ones (Bonanomi et al., 2019). New roles such as Chief Digital Office (CDO) (and departments) are increasingly created to deliver the transformation impacts of digital technologies, particularly BIM (Maskuriy et al., 2019b; Braun and Sydow, 2019; Koseoglu et al., 2019; Azzouz and Papadonikolaki, 2020).

\section{Digital Culture}

Digital technologies can be a source of disruption to existing operational culture in construction (Newman et al., 2020). To avoid shocks, digital culture needs to be embedded in the sociocultural expectations across projects, organizations, and institutions in the construction industry (Hetemi et al., 2020). Many studies have shown that BIM implementation is easier when the implementers' values, attitudes, and internal practices are receptive to the digital culture [e.g., Dallasega et al. (2018); Koseoglu et al. (2019); Azzouz and Papadonikolaki (2020)]. Additionally, such receptive values, attitudes, and internal practices prevent employee resistance to BIM implementation (Koseoglu et al., 2019; Newman et al., 2020). Accepting digital technologies is increasingly becoming a cultural necessity in construction (Newman et al., 2020), capable of speeding up DT in construction (Maskuriy et al., 2019b).

\section{External Legitimation}

Many digital technologies in construction are not solutions in and of themselves, which is apparent in blockchain, but becomes a better solution when integrated with the internet or IoT (Li et al., 2019). Legitimizing such an integration, both legally and ethically (Li et al., 2019), prescribes how to properly implement such digital technologies in an integrated manner (Papadonikolaki, 2018). In practice, construction organizations are responsible for obtaining such legitimacy (Hetemi et al., 2020) from the government (Morgan, 2019), whose role has become dominant (Hetemi et al., 2020). The government is primarily responsible for issuing directives and national initiatives that promote the integration of digital services and those that promote the interoperability of digital technologies (Koseoglu et al., 2019; Li et al., 2019). The Norway BIM manual and United Kingdom BIM level 2 mandate are some of the directives for controlling BIM instrumentality in the public domain. Deriving from the role of the government, professional institutions and professional bodies have also issuing initiatives (e.g., precontract BIM execution plan) for quasicontractual digital collaboration (Papadonikolaki, 2018; Papadonikolaki et al., 2019) and generating a common platform for BIM use among multidisciplinary actors (Morgan, 2019). Such external legitimation, either by the government or professional institutions, has become the guideline for implementing digital technologies in construction; an example is the use of BIM in public tendering in Spain (Hetemi et al., 2020). On the downside, the role of government in legitimizing digital technologies is focused mainly on BIM in the United Kingdom, the United States, China, and European countries. In contrast, other digital technologies in other countries are still left out. Regardless, a study on blockchain application in construction speculated that external legitimation through the government's role would continue with increasing attention on digital technologies in construction (Chen, 2019a; Tezel et al., 2020). 
TABLE 5 | Summary of inductive literature on barriers to DT in construction.

Threats

Complex data processing $(n=11)$

Data access and ownership $(\mathrm{n}=8)$

Lack of system integration $(n=13)$

ROI uncertainty ( $n=12$ )

Low standardization $(n=8)$

Lack of owner buy-in $(n=10)$

Displacement of old workers $(n=5)$

Existence of old business models $(n=6)$

Digital divide $(\mathrm{n}=9)$

Risk of system attacks $(n=5)$
Sources

Heusler and Kadija (2018), Chen (2019a), Chen (2019b), Koch et al. (2019), Koseoglu et al. (2019), Li et al. (2019), Maskuriy et al. (2019b), Aghimien et al. (2020a), Keskin et al. (2020), Pham et al. (2020), and Tezel et al. (2020)

Woodhead et al. (2018), Chen (2019), Koch et al. (2019), Koseoglu et al. (2019), Li et al. (2019), Singh (2019), Aghimien et al. (2020a), and Berlak et al. (2020)

Oesterreich and Teuteberg (2016), Woodhead et al. (2018), Chen (2019a), Chen (2019b), Braun and Sydow (2019), Koch et al. (2019), Koseoglu et al. (2019), Darko et al. (2020), Greif et al. (2020), Hetemi et al. (2020), Keskin et al. (2020), Succar and Poirier (2020), and Zabidin et al. (2020)

de Soto et al. (2018), Woodhead et al. (2018), Chen (2019), Koseoglu et al. (2019), Li et al. (2019), Aghimien et al. (2020a), Berlak et al. (2020), Greif et al. (2020), Newman et al. (2020), Oesterreich and Teuteberg (2016), Tezel et al. (2020), and Winch and Cha (2020)

Woodhead et al. (2018), Chen (2019a), Craveiroa et al. (2019), Koch et al. (2019), Morgan (2019), Papadonikolaki et al. (2019), Succar and Poirier (2020), and Tezel et al. (2020)

Dallasega et al. (2018), Woodhead et al. (2018), , Koch et al. (2019), Koseoglu et al. (2019), Aghimien et al. (2020a), Berlak et al. (2020), Hetemi et al. (2020), Keskin et al. (2020), Newman et al. (2020), and Winch and Cha (2020)

Woodhead et al. (2018), Braun and Sydow (2019), Koseoglu et al. (2019), Maskuriy et al. (2019), and Pan et al. (2020) Goulding et al. (2018), Woodhead et al. (2018), Koseoglu et al. (2019), Singh (2019), Keskin et al. (2020), and Tezel et al. (2020)

Goulding et al. (2018), Koseoglu and Nurtan-Gunes (2018), Papadonikolaki (2018), Bonanomi et al. (2019), Morgan (2019), Berlak et al. (2020), Newman et al. (2020), Pan et al. (2020), and Tezel et al. (2020)

Woodhead et al. (2018), Chen (2019a), Maskuriy et al. (2019a), Morgan (2019), and Tezel et al. (2020)

\section{Research}

The prospects of digital technologies such as robotization of construction sites, but which are yet to be practicable, have become the heart of funded research and development in construction (Pan et al., 2020). Practical implementation of technologies such as $3 \mathrm{D}$ printing has mostly been limited to field tests (Dallasega et al., 2018). To move forward, academic and practitioner research and development stands as a key enabler to demonstrate the practicability of digital technologies more widely (Chen, 2019b; Pan et al., 2020). While aiming for wider dissemination, it is better to start exploratorily through limited trials that academic researchers can present to industry stakeholders before embarking on practical implementation (Singh, 2019). Academic research is critical; for instance, academic researchers can employ theories that interface multiple disciplines (e.g., computer science) for theoretical exploration of digital technologies and prescribe those that are relevant to construction tasks (Singh, 2019; Tezel et al., 2020). This has created a growing ecosystem of research mavericks such as Dr. Amos Darko (Darko et al., 2020), who continually focus on expanding the research potential of digital technologies in construction (Chen, 2019b; Singh, 2019).

\section{Barriers to Digital Transformation in Construction}

Barriers suppress DT in construction. As shown in Table 2 and Figures 2, 3, the results of the open coding, axial coding, and selective coding produce ten barriers of DT in construction, namely, complex data processing, data access and ownership, system integration, return on investment uncertainty, and low standardization. Others are lack of owner buy-in, displacement of older workers, digital divide, and risk of system attacks. They are described in this section, and the summary of the literature on the strategic considerations is presented in Table 5.

\section{Complex Data Processing}

Digital technologies used in project design, construction and operation, and management operations in construction organizations generate a large amount of (semantic and geometric) data that are complex to process and analyze (Keskin et al., 2020). It is more complex when data need to be transferred from one digital technology to another (e.g., a sensor on site to an office server) (Buisman, 2018). The use of AI and ML techniques has helped process and analyze complex construction data but not without shortcomings. Real-time data processing and analytics may not be possible given the lengthy data preparation involved before the techniques can be used to obtain valid results (Heusler and Kadija, 2018; Maskuriy et al., 2019b; Chen, 2019b). One that is apparent with BIM data is the complexity of processing and analyzing construction data that are derived from different trades (Keskin et al., 2020). From studies, this prevents attempts at making sense of BIM data from constructors and facility managers involved in a large airport project (Koch et al., 2019; Koseoglu et al., 2019). This is a threat to DT in construction in the form of isolated digital solutions instead of embedding digital solutions from different disciplines (Koseoglu et al., 2019). Concerning the blockchain, the public blockchain can only process small amounts of data, limited to few transactions per second (Tezel et al., 2020), which undermines its integration with smart cities and digital twins (Chen, 2019a; Li et al., 2019). However, data processing may not be complex in small organizations that mostly generate small construction data (Pham et al., 2020).

\section{Data Access and Ownership}

Data produced in construction processes are still being treated as confidential as many construction projects and organizations struggle to achieve open-data sharing (Aghimien et al., 2020a). It creates legal issues (Maskuriy et al., 2019a) that are neither tested nor precedented ( $\mathrm{Li}$ et al., 2019). For instance, data 
ownership and rights to use data are often tied together to the detriment of data sharing/access in construction (Chen, 2019a). Data owners are overly about privacy protection (Chen, 2019a), and they treat data independently across project delivery (e.g., planning data vs. execution data) (Koch et al., 2019; Berlak et al., 2020). With multiple project phases or multiple departments involved, it leads to independent data management where data are barely shared Chen (2019a). Concerning recent BIM platforms (e.g., BIM 360), they allow data access across project phases (Koseoglu et al., 2019), but legal and interoperability issues remain to be fully addressed (Koch et al., 2019).

\section{System Integration}

Lack of system integration is the nonalignment or incompatibility of implemented digital technologies in construction (Braun and Sydow, 2019) and lack of an integrated layer of hardware, software, information flows, and connectivity (Woodhead et al., 2018). As commonly experienced in BIM implementation, the problem is escalated when different trades use incompatible software packages that are not integrated sufficiently (or interoperable) (Braun and Sydow, 2019; Koch et al., 2019). Also, deriving from the interoperability problem is the limited end-to-end integration of the new generation of digital technologies (e.g., IoT, blockchains, cloud platform, AI, and big data) across the construction value chain (Chen, 2019a). It restricts digital technologies to a specific application, focuses on a singular problem or one use-case (Woodhead et al., 2018), such as an enterprise management system (EMS) that records the wage rate of construction workers but not linked to their productivity on-site (Chen, 2019b). To avert this problem, the practice has been to combine many point solutions that rarely accept integrative use of data (Woodhead et al., 2018; Chen, 2019b), thereby leading to silo solutions (Greif et al., 2020). According to Zabidin et al. (2020), nonintegration leads to using digital technologies independently of one another, which decelerates DT in construction. For instance, a lack of integration between BIM and IoT prevents the cyber-physical potential and prevents a bidirectional information exchange between the physical and virtual environments (Zabidin et al., 2020).

\section{Low Standardization}

Compounding the lack of system integration is the lack of standards (or standardization) to guide the integration of various digital technologies in construction (Chen, 2019a). This reduces the choice of digital technologies that are installed in the technology ecosystem of construction (Woodhead et al., 2018; Tezel et al., 2020). This problem is more cumbersome in the building operation phase due to a lack of standards to guide the integration of digital technologies (Koch et al., 2019). A plethora of standard documents, such as the ISO suit of standards (Morgan, 2019; Succar and Poirier, 2020), has been released to standardize the integration of digital technologies in construction (Woodhead et al., 2018; Succar and Poirier, 2020). However, it has resulted in overstandardization, making it difficult to determine what to standardize (or not) given the influx of digital technologies implemented in construction (Succar and Poirier, 2020). Also, the ISO standards do not provide adequate guidelines for integrating digital technologies that overlap sectors (e.g., 3D printing application in the manufacturing sector) (Craveiroa et al., 2019; Succar and Poirier, 2020), which is perhaps due to the gap between the standardization approaches in the productoriented manufacturing industry and the process-oriented construction industry (Succar and Poirier, 2020). In practice, the lack of standards for integrating digital technologies that overlap sectors frustrates smart-city development (Chen, 2019a).

\section{Return on Investment Uncertainty}

Digital technologies in construction often incur high initial costs (Newman et al., 2020), and this invokes a notion of quick return on digital investment (ROI) among adopters (Woodhead et al., 2018; Berlak et al., 2020). In particular, the owner organizations in construction are fixated on the notion of benefits realization when investing in digital technologies (Winch and Cha, 2020). According to Woodhead et al. (2018), this notion fuels hesitation because of the uncertainty that often surrounds the benefits of digital technologies in construction (Oesterreich and Teuteberg, 2016). The notion encourages "future-safe" rather than aggressive investment in digital technologies (Woodhead et al., 2018; Greif et al., 2020). Consequently, the fear of loss of digital investment is created (Woodhead et al., 2018; Aghimien et al., 2020a) and reinforced by a low-profit margin in construction (Newman et al., 2020). Hesitation to invest in digital technologies is greater in small companies due to fewer incentives to recoup investment (Tezel et al., 2020). Meanwhile, it is not all gloom as assuredness in the ROI of digital investments can be achieved. From an analysis of the cost of robots, repetitive application robots in complex projects only are more economically competitive (de Soto et al., 2018). Also, assuredness in the ROI on digital investments increases where a small amount of data is generated and analyzed (Chen, 2019a). Large amount of data poses difficulties in the analytics and increases the operational costs (Chen, 2019a).

\section{Lack of Owner Buy-In}

According to Winch and Cha, 2020, the objective of implementing digital technology in construction should conform with owners' requirements and expectations of project delivery and organization performance. This guarantees not only owner buy-in in digital technologies (Hetemi et al., 2020; Keskin et al., 2020) but also the changes that may occur to the owner project and organization due to the implementation of digital technologies (Aghimien et al., 2020a; Berlak et al., 2020). For instance, digital capabilities in the owner organization need to be functional to support digital technology implementation (Newman et al., 2020; Tezel et al., 2020). However, the lack of owner buy-in in digital technologies is still pervasive in construction and their inability to adapt to the emerging changes (Koch et al., 2019). Lack of owner buy-in in digital technologies manifests through their add-on mentality of digital technologies (Papadonikolaki et al., 2019) and emphasises the partial implementation of digital technologies (Dallasega et al., 2018; Hetemi et al., 2020). It should be noted that lack of owners' buy-in does not mean an absence of digital technology 
implementation in owners' projects or organizations. The issue is that the use of digital technologies in owner projects (Koseoglu et al., 2019; Winch and Cha, 2020) has not been optimal due to the lack of owners' buy-in (Berlak et al., 2020).

\section{Displacement of Old Workers}

Owing to the dynamic development of technology, the implementation of digital technologies in construction has introduced digital capabilities that are opaque but, more worryingly, tied mainly to young people (e.g., construction informatics) (Braun and Sydow, 2019; Koseoglu et al., 2019). Contrary to the knowledge management principle (Grant, 2002), this happenstance continues to displace older people who have experiential domain knowledge that fosters DT when appropriately combined with the digital capabilities of young people in construction (Woodhead et al., 2018). In parallel, part of the problem is the threat of displacing traditional roles (e.g., material inventory) that are commonly handled by older people on construction sites with digital technologies (e.g., robots) (Woodhead et al., 2018; Pan et al., 2020). This continues to derail the experiential contribution of older people in construction. The older people, especially those occupying strategic positions in project organizations, have been found to manifest their frustrations by demonstrating opposition attitude to digital technology use in construction projects (Koseoglu et al., 2019). The characterization of aging to mean lack of skill (Pan et al., 2020) without an institutionalized age management approach to identify digital capabilities among older people is commonplace in construction and has set back DT efforts (Maskuriy et al., 2019b).

\section{Old Business Models}

The implementation of digital technologies is supposed to lead to innovative business models (where business and IT are integrated) that transform the digital construction production process (Koseoglu et al., 2019; Keskin et al., 2020). This means the elimination of physical construction (Singh, 2019) in favor of service-only construction (Keskin et al., 2020), such as IoTenabled selling of "buildings as a service" or self-organizing trades using blockchain (Woodhead et al., 2018). However, it is impossible, thereby retaining the existing (old) business models in construction (Tezel et al., 2020). Part of the problem is the lack of precedence (or use-cases) of the innovative business models in construction (Singh, 2019; Tezel et al., 2020). This condemns the innovative business models as a subjective proposition (Goulding et al., 2018). Trade-off of the existing business models remains a conflicting issue, especially for the incumbent construction organizations (Verhoef et al., 2019).

\section{Digital Divide}

The digital divide manifests in large and often incumbent construction organizations having more resources and influence to exert greater external changes and internal practices through the application of digital technologies (Morgan, 2019). Small organizations have the advantage of adapting faster to changes resulting from digital technology implementation (Morgan, 2019) but fewer resources and influence (Goulding et al., 2018; Papadonikolaki, 2018). As a result of the digital divide, blockchain's traceability and transparency functions are easily translated to business models in large construction organizations (Tezel et al., 2020). The digital divide in construction mainly favors/accentuates digital technology applications in large organizations. This automatically undermines DT in construction because the more populated small organizations in construction are left out (Berlak et al., 2020; Newman et al., 2020). Furthermore, with the dependence between large and small organizations in the supply chain (Newman et al., 2020), an inequivalent implementation of digital technologies reduces DT in construction (Craveiroa et al., 2019).

\section{System Attacks}

The increasing use of digital technologies elevates the risk of system attacks in construction (Maskuriy et al., 2019a). For instance, BIM tools are widely used digital technologies in construction, but very little has been done to secure BIM data (Maskuriy et al., 2019a). Data security in private blockchains is still prone to unsolicited data manipulations when applied in construction (Tezel et al., 2020). The study of smart city development in China has shown that data and system security can be very difficult due to persistent leakage in many digital technologies (Chen, 2019a). The strong potential of data and security breach (Koseoglu et al., 2019; Morgan, 2019) reduces client and user trust and confidence in the digital process in construction (Koseoglu et al., 2019).

\section{Construction Activity Fields and Their Digital Transformation}

The results of inductive content analysis produce six construction activity fields and their digital transformation, namely, concurrent designing and printing, construction process integration, interfirm relations, automated payment systems, digital construction, and information exchange. These provide insights into digital transformation in specific construction activity fields. Digital technology implementation can, therefore, be focused on the activity fields for increased digital transformation in construction. They are described in this section and illustrated in Figure 6.

\section{Concurrent Designing (and Printing)}

Architectural and engineering designing is a construction activity that is actively undergoing digital transformation in the construction sector. The use of digital technologies has led to a shift from symbolic 2D drawings (plans, sections, and elevations) to the creation of objects that could be modeled, visualized, exchanged, and analyzed within a $3 \mathrm{D}$ space. These characteristics enable the digital transformation of architectural and engineering designs in construction. As demonstrated in Craveiroa et al. (2019), the 3D printing technology (using the extrusion or binder jetting processes) enables the concurrent designing and construction of concrete and other polymetric construction elements. Also, Heusler and Kadija (2018) employed Artificial Intelligence to propose a semiautomatic and generative 


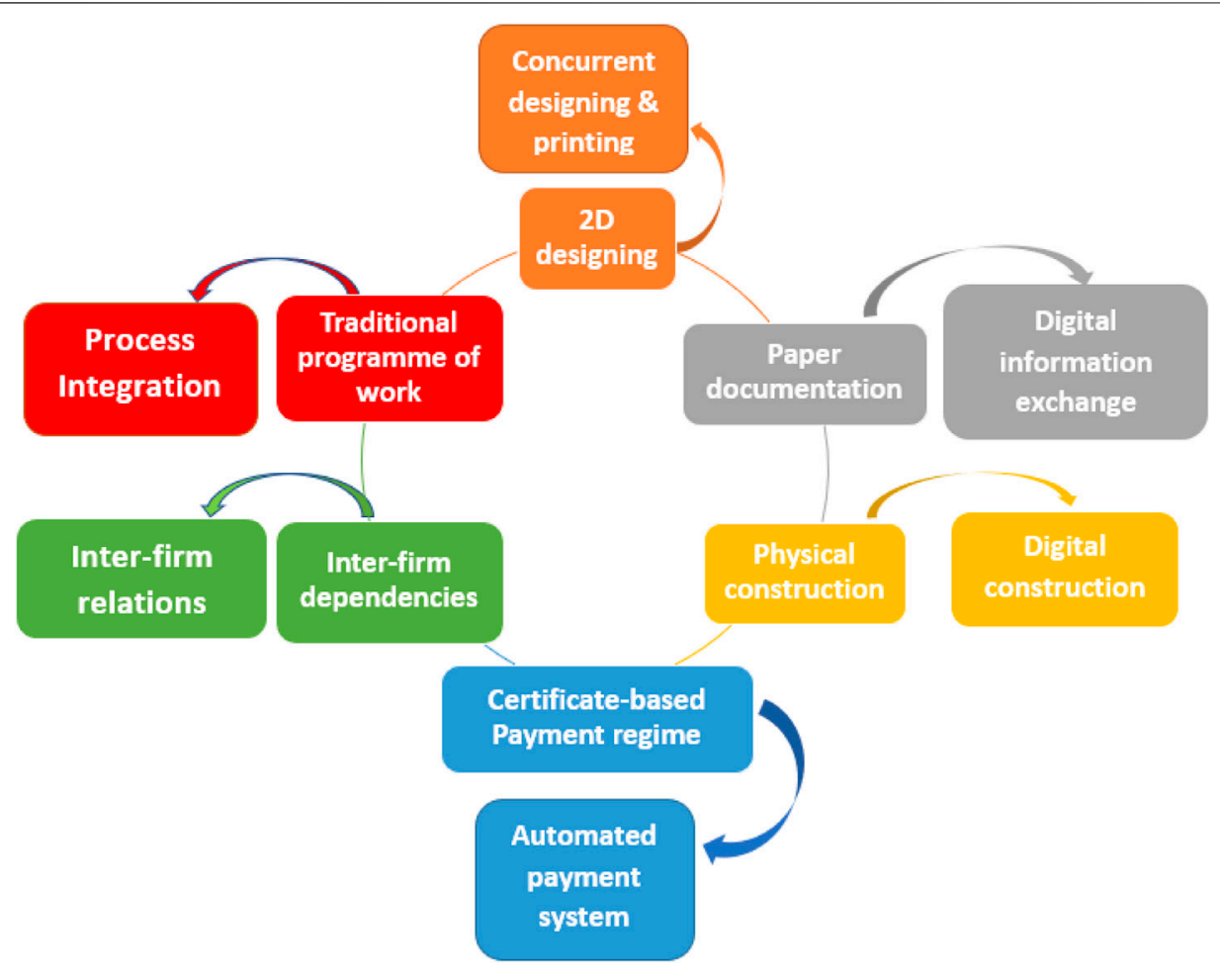

FIGURE 6 | Construction activity fields and their digital transformation.

design of façade in buildings that are both rule and intuition based.

\section{Construction Process Integration}

The implementation of digital technologies, especially BIM, in construction project delivery has integrated construction processes, comprising the people, technology, and processes. Regarding the people, BIM implementation promotes a "bind" that may manifest in similar pressures and logics experienced among the actors in an organization (Hetemi et al., 2020). Also, BIM implementation leads to streamlining construction technology ecosystem uses that increase connectivity among project parties (Keskin et al., 2020). Therefore, BIM implementation merges the intraorganizational silos in the construction process and speeds up project delivery (Koseoglu et al., 2019; Azzouz and Papadonikolaki, 2020).

\section{Interfirm Relations}

Implementing BIM for construction project delivery has progressed interfirm dependencies toward interfirm relations in construction. Traditionally, mutual relations that exist between the organizations in the construction supply chain create dense interfirm dependencies. However, concerning digital information sharing, interfirm relations imbibe a network view of innovation, which manifests conditionally. As found in the work of Papadonikolaki (2018), BIM implementation that is internally motivated (e.g., increase the quality of service) leads to more collaborative and flexible relations with other BIM implementers. Otherwise, an externally motivated BIM implementation (e.g., gain market reputation) leads to competition that prevents smooth interfirm relations (Papadonikolaki, 2018). Furthermore, BIM implementers that share similar motivations produce more consistent project outcomes (Papadonikolaki, 2018). Interfirm relations exemplify a seamless digital technology organization to create transformational impacts in the construction supply chain (Morgan, 2019).

\section{Automated Payment System}

Effecting payments to vendors and linking them to contracts is also a construction activity experiencing digital transformation in the construction sector. Although blockchain (or Distributed Ledger Technology (DLT)) is still being experimented with in many instances, it is almost generally accepted technology for automating payments and contracts in construction (Tezel et al., 2020). Li et al. (2019) introduced the "Project Bank Accounts" (PBA) that was initiated in the United Kingdom as an electronic bank account set by the client (and the main contractor) to ring-fence funds for different contractors by putting the funds into a trust. Once a contractual obligation is completed, payments are automatically made by the clients directly and simultaneously to the main contractor and vendors associated with the PBA (Tezel et al., 2020). Similarly, smart contracts can embed funds into a contract to protect contractors and vendors from insolvency and could effect payments upon automation. 


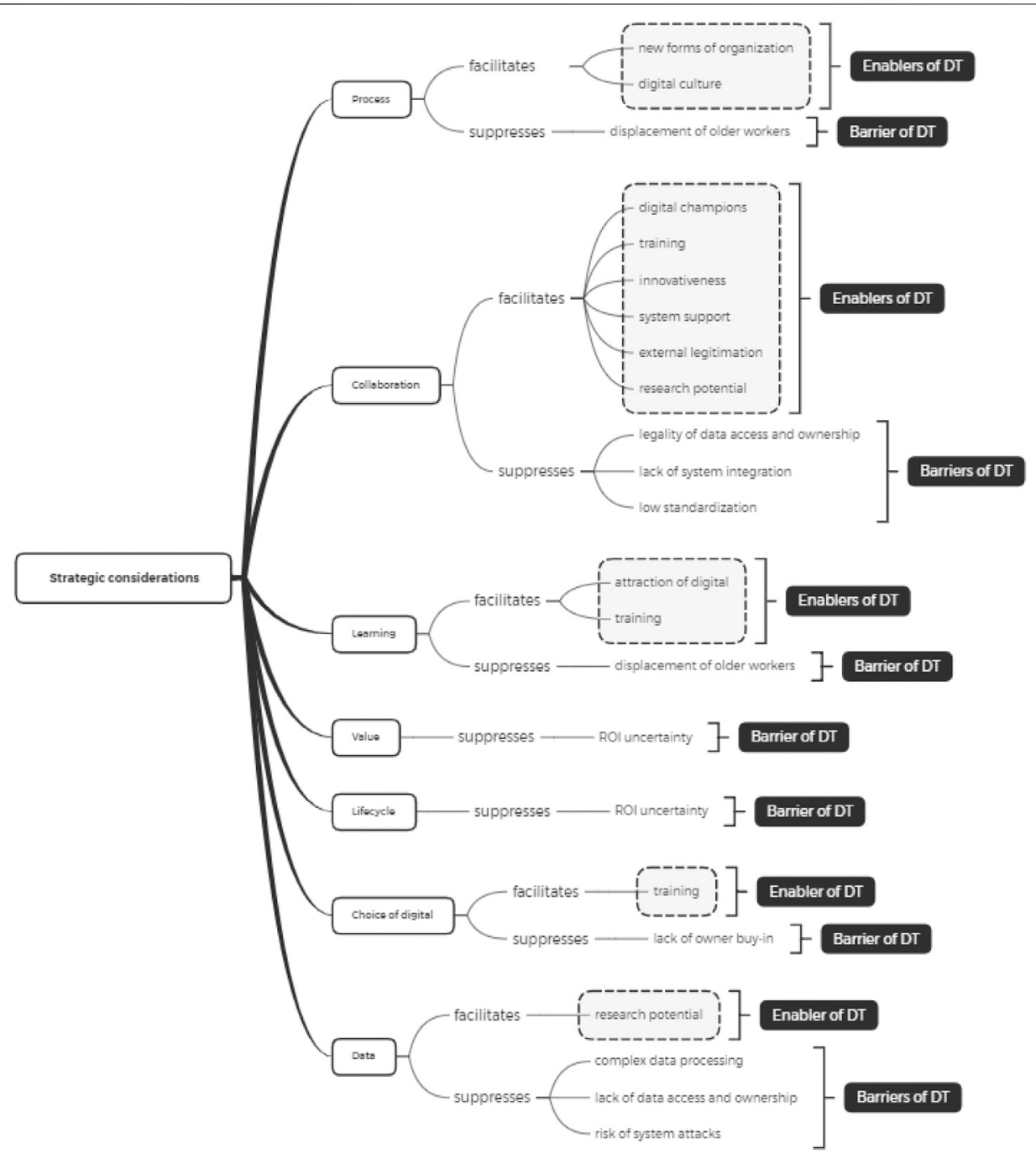

FIGURE 7 | Illustration of DT guideline in construction.

\section{Digital Construction}

The automation of excavation, movement of Earth, erection of forms or structures, purchase of materials and equipment, and other physical construction activities are increasingly implemented using digital technologies. For instance, robots have been implemented for residential wall construction (Berlak et al., 2020). Research has shown that robots increase productivity in concrete wall construction through efficient cost and time completion (de Soto et al., 2018). Another study reveals that BIM enhances project organization and controlling (Koseoglu and Nurtan-Gunes, 2018). Integrated teams using the BIM digital environment can respond immediately to project demands (Berlak et al., 2020). Therefore, BIM provides a digital construction management approach for construction managers (Koseoglu and Nurtan-Gunes, 2018). Furthermore, Greif et al. (2020) reveal the application of digital twins for automating construction site logistics. The study demonstrated the transformation of bulk silos for material storage through the application of digital twins.

\section{Information Exchange}

Digital technologies such as sensors used in construction project delivery generate data, which activates data/information exchange among integrated project team members. There is a significant loss of useful project information with a lack of a platform for information exchange or incompatible information exchange platforms (Koch et al., 2019). Increasingly, information exchange frameworks such as the "Lifecycle Information Transformation and Exchange (LITE)" framework is used for defining, managing, and integrating project and asset lifecycle information (Succar and Poirier, 2020). The LITE framework demonstrates the transformations possible with information exchange in construction. These include information flows from physical to digital assets, between small and large assets, and between assets within and beyond construction domains. 
Other possible transformations are information exchange at different scales, such as single information exchange activity or a set of activities, information exchange in a project delivery phase or complete project delivery phases, or the whole asset lifecycle.

\section{DISCUSSION}

This review reveals the contributions that research has made toward an understanding of DT in construction. The inductive framework also highlights DT in construction as a process where the implementation of digital technologies creates transformation effects that trigger strategic considerations for putting in place the enablers that facilitate transformation effects and suppressing the barriers to it. Therefore, using a diagrammatic illustration (Figure 7), the strategic considerations for facilitating specific enablers and suppressing specific barriers to transformation effects in construction were presented. Furthermore, they are described in the following section to serve as DT guideline for the implementers of digital technologies in construction. In practice, it is expected that the guideline will help construction stakeholders to respond and adapt to DT in construction. Acknowledging that the DT guideline should be domain sensitive (Korachi and Bounabat, 2020), the previous studies on how to use DT guidelines in the IT, automation, financial services, and media sectors (Chanias and Hess, 2016; Chanias, 2017) were sector specific and did not specify guidelines for DT in the construction sector as suggested in the following.

Process. This strategic consideration facilitates two enablers of DT in construction, namely, new forms of organization and digital culture. Both the enablers relate to internal processes that foster (or hinder) organization objectives (including project organization). Among incumbent construction organizations, particularly the small ones, the diffusion of digital technologies is important to ensure that all internal members are involved in the implementation (Shibeika and Harty, 2015). This strategic consideration emphasizes the process approach to diffuse digital technologies, such as whether a digital technology should be trialed among a segment of people in an organization before extending it to other segments in the organization. Similarly, the strategic consideration emphasizes on a process-centric approach to embedding the digital culture that shapes the implementation of digital technologies among internal members in construction organizations. Furthermore, this strategic consideration suppresses only a barrier of DT in construction, namely, displacement of older workers. Specifying a process for identifying digital capabilities corresponding to age reduces the tendency to regard older workers as digitally naive in construction.

Collaboration. This strategic consideration facilitates six enablers and suppresses three barriers of DT in construction. Therefore, it is considered the most influential strategic consideration in this study. The six enablers are digital champions, training, innovativeness, and systems support. Others are legitimation and research. Digital champions are often in leadership positions and strongly motivated to help others understand the benefits and implementation of digital technologies (Grand Union Holding Group, 2020). This strategic consideration emphasizes the collaborative use of digital technologies among professionals, projects, and organizations, allowing digital champions to have greater influence. Both training and innovativeness enablers reiterate how the transformation effects of digital technology implementation overlap construction and other sectors such as the manufacturing sector. To this end, the emphasis on collaboration helps to bridge the gaps in digital technology implementation between the construction and other sectors. Regarding system support, it emphasizes after-sales support from product manufacturers and can extend to cocreation between manufacturers and product users in construction with appropriate collaboration strategies. Cocreation leads to the production of customized digital technologies in construction (Woodhead et al., 2018). Both legitimation and research enablers reiterate the construction stakeholders, including government and professional entities, who work together to ensure the integrated functioning of digital technologies. Strategic collaboration among these stakeholders ensures that beneficial DT is achieved in construction (Ezeokoli et al., 2016).

Furthermore, the three barriers are data access and ownership, lack of system integration, and low standardization. Regarding the legality of data access and ownership, the strategic considerations that promote collaborative use of digital technologies foster joint ownership of data and prevent users from independent data management (Pauwels et al., 2017) with significant legal implications (Fan et al., 2018). Also, regarding the lack of system integration, increasing digitization through a technology-enabled collaborative ecosystem reduces software incompatibility and point solutions in construction (Woodhead et al., 2018). Consequently, it increases the standardization of digital technologies and ease of implementing them in construction.

Learning. This strategic consideration facilitates two enablers of DT in construction, namely, the attraction of digital and training. Regarding the attraction of digital, the strategic consideration specifying model updates and upgrades creates opportunities to learn new things from the implementation of digital technologies. Also, it is a key attraction for young construction employees (Soman and Whyte, 2020). Also, regarding training, model updates and upgrades raise the need for digital training in construction. Meanwhile, this strategic consideration suppresses only a barrier to DT in construction, namely, displacement of older workers. The strategy that promotes inclusive digital training helps older workers increase their digital capabilities and obtain their inputs in digital learning.

Value. This strategic consideration suppresses only a barrier to DT in construction, namely, ROI uncertainty. It emphasizes the development of the business case for digital technologies, which in the case of BIM helps identify the benefits derivable, thereby removing the fears of loss of digital investment (Reddy, 2011; Raji et al., 2020).

Lifecycle. Like the value strategic consideration, this one also suppresses only the DT's ROI uncertainty barrier in construction. This strategic consideration overviews digital technologies as a 
long-term investment that extends over the project and organization lifecycle. This consideration quells the notion of quick ROI on digital investment in construction.

Choice of Digital. This strategic consideration facilitates an enabler of DT in construction, namely, training. It emphasizes choosing the digital technologies that can be easily implemented, which shortens the digital learning curve for the implementers in construction. Also, this strategic consideration suppresses a barrier to DT in construction, namely, lack of owner buy-in. The strategic consideration emphasizes aligning the choice of digital technologies to the objectives of project owners to serve as motivation to increase their investment in digital.

Data. This strategic consideration facilitates an enabler of DT in construction, namely, research. The emphasis is to make data from digital technologies available when implemented, and this increases the potential for further digital research in construction. Furthermore, this strategic consideration suppresses three enablers of DT in construction, namely, complex data processing, data access and ownership, and risk of system attacks. Regarding data processing and data access and ownership, this strategic consideration emphasizes making data available across platforms and project phases to ease data analytics and decision making and enhance data sharing and data dependency. Also, making data available should encompass data breach and security measures for preventing system attacks (Chong and Diamantopoulos, 2020).

This study identified that the implementation of digital technologies divided into digital data, automation system, digital access, and connectivity components had increased the potential of digital transformation in construction. The existing knowledge of digital transformation in other sectors such as IS and business economics does not provide an understanding of digital transformation in construction. However, with increasing literature on the implementation of digital technologies, this

\section{REFERENCES}

Agarwal, R., Chandrasekaran, S., and Sridhar, M. (2016). The Digital Future of Construction. Retrieved from https://www.globalinfrastructureinitiative. $\mathrm{com} /$ sites/default/files/pdf/The-digital-future-of-construction-Oct2016.pdf.

Aghimien, D., Aigbavboa, C., Oke, A., Thwala, W., and Moripe, P. (2020a). Digitalization of Construction Organisations - a Case for Digital Partnering. International Journal of Construction Management, 1-10. doi:10.1080/ 15623599.2020 .1745134

Aghimien, D. O., Aigbavboa, C. O., and Oke, A. E. (2020b). Critical success Factors for Digital Partnering of Construction Organisations-A Delphi Study. Engineering, Construction and Architectural Management.

Autodesk (2020). Digital Transformation: The Future of Connected Construction. Retrieved from http://constructioncloud.autodesk.com/rs/572-JSV-775/ images/Autodesk-IDC-Digital\%20Transformation_The-Future-of-ConnectedConstruction.pdf.

Azzouz, A., and Papadonikolaki, E. (2020). Boundary-spanning for Managing Digital Innovation in the AEC Sector. Architectural Eng. Des. Manag. 16, 1-18. doi:10.1080/17452007.2020.1735293

Berger, R. (2016). "Digitization in the Construction Industry," in Competence Center Civil Economics (Munich: Roland Berger GmbH).

Berlak, J., Hafner, S., and Kuppelwieser, V. G. (2020). Digitalization's Impacts on Productivity: a Model-Based Approach and Evaluation in Germany's Building study took stock of the knowledge through an inductive literature review to provide an understanding of digital transformation in construction. Following the inductive review, the inductive framework that was developed highlights digital transformation in construction as a process where the implementation of digital technologies creates transformation effects that trigger strategic considerations for putting in place the enablers that facilitate transformation effects and suppressing the barriers to it. Subsequently, the variables of strategic considerations, enablers, and barriers identified from the review were described. Finally, the strategic considerations for facilitating specific enablers and suppressing specific barriers were discussed and presented as digital transformation guidelines in construction using an illustration (Figure 7). This study concluded that the implementation of digital technologies has increased the understanding of and provided a solid basis for digital transformation in construction. Also, the digital transformation in construction activity fields is concurrent designing and printing, construction process integration, interfirm relations, automated payment systems, digital construction, and information exchange. Regarding research limitation, the findings were obtained from 36 journal publications. However, it was acknowledged in this article that the subject and the research about it are still emerging. Therefore, this study employed an inductive review approach that isolated conference publications to obtain quality findings. Also, the approach helped in capturing the relevant concepts in the emerging field.

\section{AUTHOR CONTRIBUTIONS}

AO carried out the literature review and discussion of findings. MS overviewed the manuscript and organized the contents.

Construction Industry. Prod. Plann. Control. 32, 1-11. doi:10.1080/ 09537287.2020.1740815

Bharadwaj, A., El Sawy, O. A., El Sawy, O. A., Pavlou, P. A., and Venkatraman, N. (2013). Digital Business Strategy: toward a Next Generation of Insights. Misq 37, 471-482. doi:10.25300/misq/2013/37:2.3

Böhm, A. (2004). "Theoretical Coding: Text Analysis in Grounded Theory," in $A$ Companion to Qualitative Research. Editors D. U. Flick, E. von Kardorff, and I. Steinke (London: Sage), 270-275.

Bonanomi, M. M., Hall, D. M., Staub-French, S., Tucker, A., and Talamo, C. M. L. (2019) The Impact of Digital Transformation on Formal and Informal Organizational Structures of Large Architecture and Engineering Firms. Engineering, Construction Architectural Management 27 (4), 872-892. doi:10.1007/978-3-030-19701-8

Braun, T., and Sydow, J. (2019). Selecting Organizational Partners for Interorganizational Projects: The Dual but Limited Role of Digital Capabilities in the Construction Industry. Project Manag. J. 50 (4), 398-408. doi:10.1177/8756972819857477

Buisman, A. (2018). How Are Engineering and Construction Companies Adapting Digital to Their Businesses.

Chadegani, A. A., Salehi, H., Yunus, M. M., Farhadi, H., Fooladi, M., Farhadi, M., et al. (2013). A Comparison between Two Main Academic Literature Collections: Web of Science and Scopus Databases. Asian Soc. Sci. 9 (5), 18-26. doi:10.5539/ass.v9n5p18

Chanias, S., and Hess, T. (2016). Understanding Digital Transformation Strategy Formation: Insights from Europe's Automotive Industry. Chiayi, Taiwan: Paper Presented at the Pacific Asia Conference on Information Systems. 
Chanias, S. (2017). Mastering Digital Transformation: The Path of a Financial Services Provider towards a Digital Transformation Strategy.

Chen, X. (2019a). The Development Trend and Practical Innovation of Smart Cities under the Integration of New Technologies. Front. Eng. Manag. 6 (4), 485-502. doi:10.1007/s42524-019-0057-9

Chen, Z. (2019b). Grand Challenges in Construction Management. Front. Built Environ. 5, 31. doi:10.3389/fbuil.2019.00031

Chong, H.-Y., and Diamantopoulos, A. (2020). Integrating Advanced Technologies to Uphold Security of Payment: Data Flow Diagram. Automation in construction 114, 103158. doi:10.1016/j.autcon.2020.103158

Craveiroa, F., Duartec, J. P., Bartoloa, H., and Bartolod, P. J. (2019). Additive Manufacturing as an Enabling Technology for Digital Construction: A Perspective on Construction 4.0. Sust. Dev. 4, 6. doi:10.1016/ j.autcon.2019.03.011

Dallasega, P., Rauch, E., and Linder, C. (2018). Industry 4.0 as an Enabler of Proximity for Construction Supply Chains: A Systematic Literature Review. Comput. Industry 99, 205-225. doi:10.1016/j.compind.2018.03.039

Darko, A., Chan, A. P. C., Adabre, M. A., Edwards, D. J., Hosseini, M. R., and Ameyaw, E. E. (2020). Artificial Intelligence in the AEC Industry: Scientometric Analysis and Visualization of Research Activities. Automation in construction 112, 103081. doi:10.1016/j.autcon.2020.103081

de Soto, B. G., Agustí-Juan, I., Hunhevicz, J., Joss, S., Graser, K., Habert, G., et al. (2018). Productivity of Digital Fabrication in Construction: Cost and Time Analysis of a Robotically Built wall. Automation in construction 92, 297-311. doi:10.1016/j.autcon.2018.04.004

Deraman, R., Wang, C., Yap, J. B. H., Li, H., and Mohd-Rahim, F. A. (2019). Developing Internet Online Procurement Frameworks for Construction Firms. Future Internet 11 (6), 136. doi:10.3390/fi11060136

Ezeokoli, F. O., Okolie, K. C., Okoye, P. U., and Belonwu, C. C. (2016). Digital Transformation in the Nigeria Construction Industry: The Professionals' View. wjcat 4 (3), 23-30. doi:10.13189/wjcat.2016.040301

Fan, S.-L., Lee, C.-Y., Chong, H.-Y., and Skibniewski, M. J. (2018). A Critical Review of Legal Issues and Solutions Associated with Building Information Modelling. Technol. Econ. Dev. economy 24 (5), 2098-2130. doi:10.3846/ tede.2018.5695

Gerbert, P., Castagnino, S., Rothballer, C., Renz, A., and Filitz, R. (2016). Digital in Engineering and Construction: The Transformative Power of Building Information Modeling.

Goulding, J. S., Ezcan, V., and Sutrisna, M. (2018). Securing the Embeddedness of Psychosocial Diffusion Indicators into the Turkish Construction Industry. J. Financial Manag. Property Construction 23 (3), 1366-4387. doi:10.1108/ JFMPC-10-2017-0040

Grand Union Holding Group (2020). Digital Champions. Retrieved from https:// www.guhg.co.uk/support/getting-online/digital_champions/.

Grant, R. M. (2002). The Knowledge-Based View of the Firm, 17.

Greif, T., Stein, N., and Flath, C. M. (2020). Peeking into the Void: Digital Twins for Construction Site Logistics. Comput. Industry 121, 103264. doi:10.1016/ j.compind.2020.103264

Hausberg, J. P., Liere-Netheler, K., Packmohr, S., Pakura, S., and Vogelsang, K. (2019). Research Streams on Digital Transformation from a Holistic Business Perspective: a Systematic Literature Review and Citation Network Analysis. J. Business Econ. 89 (8-9), 931-963. doi:10.1007/s11573-019-00956-Z

Henriette, E., Feki, M., and Boughzala, I. (2015). “The Shape of Digital Transformation: a Systematic Literature Review,” in MCIS 2015 Proceedings, 431-443.

Hetemi, E., Ordieres-Meré, J., and Nuur, C. (2020). An Institutional Approach to Digitalization in Sustainability-Oriented Infrastructure Projects: The Limits of the Building Information Model. Sustainability 12 (9), 3893. doi:10.3390/ su12093893

Heusler, W., and Kadija, K. (2018). Advanced Design of Complex Façades. Intell. Buildings Int. 10 (4), 220-233. doi:10.1080/17508975.2018.1493979

Hull, S. (2013). Doing Grounded Theory: Notes for the Aspiring Qualitative Analyst. Cape Town, South Africa: University of Cape Town: Division of Geomatics.

Ibem, E. O., and Laryea, S. (2014). Survey of Digital Technologies in Procurement of Construction Projects. Automation in construction 46, 11-21. doi:10.1016/ j.autcon.2014.07.003

Ismail, M. H., Khater, M., and Zaki, M. (2017). Digital Business Transformation and Strategy: What Do We Know So Far. Cambridge Service Alliance, 10.
Keskin, B., Salman, B., and Ozorhon, B. (2020). Airport Project Delivery within BIM-Centric Construction Technology Ecosystems. Eng., Constr. Archit. Manage. 28 (2), 530-548.

Koch, C., Hansen, G. K., and Jacobsen, K. (2019). Missed Opportunities: Two Case Studies of Digitalization of FM in Hospitals. Facilities 37 (7-8), 381-394.

Koeleman, J., Ribeirinho, M. J., Rockhill, D., Sjödin, E., and Strube, G. (2019). Decoding Digital Transformation in Construction.

Korachi, Z., and Bounabat, B. (2020). General Approach for Formulating a Digital Transformation Strategy. J. Comp. Sci. 16 (4), 493-507. doi:10.3844/ jcssp.2020.1451.1464

Koseoglu, O., Keskin, B., and Ozorhon, B. (2019). Challenges and Enablers in BIMEnabled Digital Transformation in Mega Projects: The Istanbul New Airport Project Case Study. Buildings 9 (5), 115. doi:10.3390/buildings 9050115

Koseoglu, O., and Nurtan-Gunes, E. T. (2018). Mobile BIM Implementation and Lean Interaction on Construction Site. Eng. Constr. Archit. Manage. 25 (10), 1298-1321.

KPMG (2019). Future-Ready Index: Leaders and Followers in the Engineering \& Construction Industry. Retrieved from https://home.kpmg/ie/en/home/ insights/2019/05/global-construction-survey-future-ready-2019.html.

Kyngäs, H. (2020). "Inductive Content Analysis," in The Application of Content Analysis in Nursing Science Research (Springer), 13-21. doi:10.1007/978-3-03030199-6_2

Lavikka, R. H., Lehtinen, T., and Hall, D. (2017). Co-creating Digital Services with and for Facilities Management. Facilities 35 (9-10), 543-556.

Li, J., Greenwood, D., and Kassem, M. (2019). Blockchain in the Built Environment and Construction Industry: A Systematic Review, Conceptual Models and Practical Use Cases. Automation in construction 102, 288-307. doi:10.1016/ j.autcon.2019.02.005

Maskuriy, R., Selamat, A., Ali, K. N., Maresova, P., and Krejcar, O. (2019a). Industry 4.0 for the Construction Industry-How Ready Is the Industry? Appl. Sci. 9 (14), 2819. doi:10.3390/app9142819

Maskuriy, R., Selamat, A., Maresova, P., Krejcar, O., and Olalekan, O. O. (2019b). Industry 4.0 for the Construction Industry: Review of Management Perspective. Economies 7 (3), 68. doi:10.3390/economies7030068

Morakanyane, R., Grace, A. A., and O’Reilly, P. (2017). “Conceptualizing Digital Transformation in Business Organizations: A Systematic Review of Literature," in Paper Presented at the Bled eConference. doi:10.18690/978-961-286043-1.30

Morgan, B. (2019). Organizing for Digitalization through Mutual Constitution: The Case of a Design Firm. Construction Manag. Econ. 37 (7), 400-417. doi:10.1080/01446193.2018.1538560

Murray, S. (2018). Five Keys to Unlocking Digital Transformation in Engineering and Construction. Boston Consulting Group: A Global Industry Council Report.

Nadkarni, S., and Prügl, R. (2020). Digital Transformation: A Review, Synthesis and Opportunities for Future Research. Manag. Rev. Q. 71, 233-341. doi:10.1007/s11301-020-00185-7

Newman, C., Edwards, D., Martek, I., Lai, J., Thwala, W. D., and Rillie, I. (2020). Industry 4.0 Deployment in the Construction Industry: A Bibliometric Literature Review and UK-based Case Study. Smart Sustainable Built Environ. doi:10.1108/SASBE-02-2020-0016

Oesterreich, T. D., and Teuteberg, F. (2016). Understanding the Implications of Digitisation and Automation in the Context of Industry 4.0: A Triangulation Approach and Elements of a Research Agenda for the Construction Industry. Comput. Industry 83, 121-139. doi:10.1016/ j.compind.2016.09.006

Pan, M., Linner, T., Pan, W., Cheng, H., and Bock, T. (2020). Structuring the Context for Construction Robot Development through Integrated Scenario Approach. Automation in construction 114, 103174. doi:10.1016/ j.autcon.2020.103174

Papadonikolaki, E. (2018). Loosely Coupled Systems of Innovation: Aligning BIM Adoption with Implementation in Dutch Construction. J. Manag. Eng. 34 (6), 05018009. doi:10.1061/(asce)me.1943-5479.0000644

Papadonikolaki, E., van Oel, C., and Kagioglou, M. (2019). Organising and Managing Boundaries: A Structurational View of Collaboration with Building Information Modelling (BIM). Int. J. project Manag. 37 (3), 378-394. doi:10.1016/j.ijproman.2019.01.010 
Pauwels, P., Zhang, S., and Lee, Y.-C. (2017). Semantic Web Technologies in AEC Industry: A Literature Overview. Automation in construction 73, 145-165. doi:10.1016/j.autcon.2016.10.003

Pham, K.-T., Vu, D.-N., Hong, P. L. H., and Park, C. (2020). 4D-BIM-Based Workspace Planning for Temporary Safety Facilities in Construction SMEs. Ijerph 17 (10), 3403. doi:10.3390/ijerph17103403

Raji, M., Ogunsemi, D. R., and Olanipekun, A. O. (2020). "Assessment of the Willingness of Quantity Surveyors to Pay for 5D BIM," in Paper Presented at the Proceedings of the 5th Research Conference of the NIQS (RECON 5) (Minna). doi:10.32655/africacurrentissues.2020.21

Reddy, K. P. (2011). BIM for Building Owners and Developers: Making a Business Case for Using BIM on Projects. John Wiley \& Sons. doi:10.1002/ 9781119572602

Reis, J., Amorim, M., Melão, N., and Matos, P. (2018). “Digital Transformation: a Literature Review and Guidelines for Future Research," in Paper Presented at the World Conference on Information Systems and Technologies.

Sepasgozar, S. M., and Loosemore, M. (2017). The Role of Customers and Vendors in Modern Construction Equipment Technology Diffusion. Eng., Constr. Architectural Manag. 24 (6), 1203-1221.

Shapiro, I., Rouse, A., and Cohron, M. (2019). Building the Future of Construction with Digital Transformation. Retrieved from https:/www.bdo.com/insights/ industries/real-estate/building-the-future-of-construction-with-digital-t.doi:10.1287/ d3d9bebb-394e-4362-bdf8-6ad8ab5c3a20

Shibeika, A., and Harty, C. (2015). Diffusion of Digital Innovation in Construction: a Case Study of a UK Engineering Firm. Construction Manag. Econ. 33 (5-6), 453-466. doi:10.1080/01446193.2015.1077982

Singh, V. (2019). Digitalization, BIM Ecosystem, and the Future of Built Environment. Eng., Constr. Architectural Manag., 1-18. doi:10.1108/ECAM01-2018-0004

Soman, R. K., and Whyte, J. K. (2020). Codification Challenges for Data Science in Construction. J. construction Eng. Manag. 146 (7), 04020072. doi:10.1061/(asce) co.1943-7862.0001846

Succar, B., and Poirier, E. (2020). Lifecycle Information Transformation and Exchange for Delivering and Managing Digital and Physical Assets. Automation in construction 112, 103090. doi:10.1016/j.autcon.2020.103090

Sutrisna, M., and Setiawan, W. (2016a). 14 the Application of Grounded Theory Methodology in Built Environment researchResearch Methodology in the Built Environment: A Selection of Case Studies, 231.

Sutrisna, M., and Setiawan, W. (2016b). "The Application of Grounded Theory Methodology in Built Environment Research," in Research Methodology in the Built Environment: A Selection of Case Studies. Editors V. Ahmed, A. Opoku, and Z. Aziz (Taylor \& Francis), 231.
Tezel, A., Papadonikolaki, E., Yitmen, I., and Hilletofth, P. (2020). Preparing Construction Supply Chains for Blockchain Technology: An Investigation of its Potential and Future Directions. Front. Eng. Manag. 7, 1-17. doi:10.1007/ s42524-020-0110-8

Verhoef, P. C., Broekhuizen, T., Bart, Y., Bhattacharya, A., Dong, J. Q., Fabian, N., et al. (2019). Digital Transformation: A Multidisciplinary Reflection and Research Agenda. J. Business Res. 122, 889-901. doi:10.1016/ j.jbusres.2019.09.022

Vial, G. (2019). Understanding Digital Transformation: A Review and a Research Agenda. J. Strateg. Inf. Syst. 28 (2), 118-144. doi:10.1016/j.jsis.2019.01.003

Webster, J., and Watson, R. T. (2002). Analyzing the Past to Prepare for the Future: Writing a Literature Review. MIS Quarterly 26 (2), 13-23.

Winch, G. M., and Cha, J. (2020). Owner Challenges on Major Projects: The Case of UK Government. Int. J. project Manag. 38 (3), 177-187. doi:10.1016/ j.ijproman.2020.03.001

Wolfswinkel, J. F., Furtmueller, E., and Wilderom, C. P. M. (2013). Using Grounded Theory as a Method for Rigorously Reviewing Literature. Eur. J. Inf. Syst. 22 (1), 45-55. doi:10.1057/ejis.2011.51

Woodhead, R., Stephenson, P., and Morrey, D. (2018). Digital Construction: From point Solutions to IoT Ecosystem. Automation in construction 93, 35-46. doi:10.1016/j.autcon.2018.05.004

Yang, J.-B., and Chou, H.-Y. (2019). Subjective Benefit Evaluation Model for Immature BIM-Enabled Stakeholders. Automation in construction 106, 102908. doi:10.1016/j.autcon.2019.102908

Zabidin, N. S., Belayutham, S., and Ibrahim, C. K. I. C. (2020). A Bibliometric and Scientometric Mapping of Industry 4.0 in Construction. J. Inf. Tech. Construction (Itcon) 25 (17), 287-307. doi:10.36680/j.itcon.2020.017

Zima, K., Plebankiewicz, E., and Wieczorek, D. (2020). A SWOT Analysis of the Use of BIM Technology in the Polish Construction Industry. Buildings 10 (1), 16. doi:10.3390/buildings10010016

Conflict of Interest: The authors declare that the research was conducted in the absence of any commercial or financial relationships that could be construed as a potential conflict of interest.

Copyright (c) 2021 Olanipekun and Sutrisna. This is an open-access article distributed under the terms of the Creative Commons Attribution License (CC $B Y)$. The use, distribution or reproduction in other forums is permitted, provided the original author(s) and the copyright owner(s) are credited and that the original publication in this journal is cited, in accordance with accepted academic practice. No use, distribution or reproduction is permitted which does not comply with these terms. 